\title{
Inovação, cooperação e aprendizado no setor de software no Brasil: análise exploratória baseada no conceito de Arranjos Produtivos Locais (APLs) ${ }^{1}$
}

\author{
Jorge Britto ${ }^{2}$ \\ Fabio Stallivieri $^{3}$
}

\begin{abstract}
Resumo
O artigo procura articular a discussão sobre o processo de construção de competências na produção de software no Brasil à distribuição espacial dessas atividades, utilizando para isso um referencial analítico baseado no conceito de "arranjos produtivos locais" (APLs), no qual ressalta-se a importância da dimensão local-institucional para o aprofundamento de diferentes formas de aprendizado e para o reforço do potencial inovativo e da competitividade industrial. A análise realizada desdobra-se em cinco seções. A primeira seção apresenta uma caracterização geral do setor e do referencial analítico utilizado. A segunda seção apresenta um panorama sintético da evolução do setor de software no Brasil no período recente. A terceira seção procura discutir aspectos relacionados à distribuição espacial da indústria, com base em informações secundárias. A quarta seção desenvolve uma análise exploratória sobre a heterogeneidade espacial da indústria, utilizando informações primárias sobre arranjos produtivos dedicados à produção de software, as quais são trabalhadas através de técnicas de estatística multivariada, visando identificar diferentes padrões relativos a processos de aprendizado e inovação existentes nesses arranjos. Uma última seção sintetiza as principais conclusões do trabalho.
\end{abstract}

Palavras-chave: Indústria de software; Inovação e cooperação; Clusters industriais - Software; Arranjos produtivos locais; Análise cross-sector.

\section{Abstract \\ Innovation, cooperation and learning in the Brazilian software industry: exploratory analysis based on the concept of local productive systems (LPSs)}

The analysis seeks to explore analytical and methodological issues associated to the study of learning, innovation and competence building in Brazilian software industry. Contrasting with a strictly sectoral focus, our hypothesis is that the territorial proximity plays an important role to the improvement of learning and to the strengthening of firms' competitiveness and innovativeness. The analysis uses the concept of "local productive systems" in order to capture the importance of local and institutional conditions to the improvement of learning and to the strengthening of innovativeness and competitiveness. The paper is organized as follow. The first section presents some structural characteristics of the software industry, as well as the analytical framework of the analysis. The second section presents some figures about the Brazilian software market, its industrial structure and the strategies adopted by software firms. The third section tries to discuss some

(1) Trabalho recebido em outubro de 2008 e aprovado em fevereiro de 2009.

(2) Professor do Departamento de Economia da Universidade Federal Fluminense (UFF), Niterói, RJ, Brasil. E-mail: jbrit@terra.com.br.

(3) Professor do Departamento de Economia da Universidade Federal Fluminense (UFF) < Niterói, RJ, Brasil. E-mail: fabio_stallivieri@yahoo.com.br. 
Jorge Britto / Fabio Stallivieri

characteristics of the spatial distribution of software activities in the Brazilian economy. The fourth section develops an exploratory analysis about the territorial heterogeneity of the industry. This analysis is articulated to a discussion about learning, innovation and competence building processes in local software productive systems. Specifically, the analysis explores the empirical evidences emerging from a survey of four case studies of local productive systems in the industry. These evidences are manipulated through multivariate techniques in order to identify different clusters of firms with similar characteristics of the learning, innovation and competence building processes. Finally, the last section presents some conclusive remarks of the analysis.

Key words: Software industry; Innovation and cooperation; Industrial clusters - software; Local productive systems: cross-sector analysis.

JEL 014, 031, 054.

\section{Introdução}

No contexto de uma economia crescentemente "baseada no conhecimento", a importância da produção de software decorre não apenas do seu papel como instrumento que viabiliza a incorporação do conhecimento em produtos, serviços e sistemas, mas também em função da sua importância para a difusão de tecnologias de informação e telecomunicação entre organizações, instituições e a população em geral. No início da década atual (2001), as atividades de software no Brasil correspondiam ao sétimo maior mercado mundial, em termos de vendas domésticas, as quais atingiam aproximadamente US\$ 7,7 bilhões. Entre 1991 e 2001, a participação da indústria de software no PIB brasileiro evoluiu de $0,27 \%$ para $0,71 \%$. Em 2006, estimativas de empresas de consultoria especializadas indicavam que o faturamento do setor atingia algo em torno de US\$ 9,05 bilhões, equivalendo a uma participação de aproximadamente 0,85\% do PIB (IDC, 2007). Ao longo da trajetória recente de evolução do setor, expressivos investimentos foram realizados na acumulação de competências produtivas e tecnológicas e no desenvolvimento de articulações interindustriais com diversas atividades. Essa evolução beneficiou-se de um conjunto de políticas que, não obstante algumas vicissitudes, possibilitaram a formação de mão de obra especializada e a montagem de uma infraestrutura expressiva, criando estímulos importantes para o surgimento e consolidação de novos negócios no setor.

Este texto procura articular a discussão sobre o processo de construção de competências na produção de software no Brasil à distribuição espacial dessas atividades, utilizando para isso um referencial analítico baseado no conceito de “arranjos produtivos locais" (APLs), os quais estariam associados à aglomeração espacial de agentes econômicos, políticos e sociais envolvidos com um conjunto específico de atividades produtivas, na qual se estruturam vínculos e relações de interdependência. Por meio desses vínculos, origina-se um processo de aprendizagem que possibilita a introdução de inovações de produtos, processos e formatos organizacionais, gerando maior competitividade para as empresas 
integradas ao arranjo. A abordagem metodológica de arranjos e sistemas produtivos locais destaca o papel central da inovação e do aprendizado interativo, como fatores de competitividade sustentada (Cassiolato; Lastres, 2003). Nessa perspectiva analítica, particular ênfase é atribuída à investigação de processos de aprendizagem, cooperação e inovação que ocorrem em espaços geográficos específicos. Um aspecto fundamental da dinâmica de operação desses arranjos diz respeito à consolidação de práticas cooperativas entre agentes, as quais resultam em processos conjuntos de capacitação e aprendizado, responsáveis pela intensificação do ritmo de introdução de inovações e pela geração de diversos tipos de ganhos (em termos do aumento da eficiência produtiva e da ampliação de mercados, por exemplo) que reforçam o desempenho competitivo das empresas integradas a tais arranjos.

Não obstante a percepção da importância dos processos localizados de aprendizado como elemento característico central desses arranjos, existem ainda lacunas consideráveis na análise tanto das formas de mensuração desses processos como do seu impacto efetivo sobre o desempenho inovativo de empresas neles inseridas. A análise desenvolvida a seguir sugere que é possível integrar informações levantadas através de questionários aplicados junto a empresas integradas a esses arranjos de modo a captar as principais características dos processos interativos de aprendizado. A análise desenvolvida constitui uma tentativa de obter-se, a partir dos questionários de pesquisas empíricas, algum tipo de mensuração das formas de interação, cooperação e aprendizado em arranjos produtivos locais, utilizando o setor de software como ilustração. Esses elementos podem ser integrados de forma a captar uma determinada "dinâmica interna" subjacente à operação de diferentes arranjos produtivos associados ao setor de software. A partir desse tipo de procedimento, seria possível avaliar as possibilidades de um determinado arranjo evoluir ao longo de uma trajetória "virtuosa" de fortalecimento da capacitação inovativa dos agentes neles inseridos.

A análise realizada desdobra-se em cinco seções. A primeira seção apresenta uma caracterização geral do setor investigado. A segunda seção apresenta um panorama sintético da evolução do setor de software no Brasil no período recente, com ênfase nas características dos esforços inovativos da indústria. A terceira seção utiliza um recorte analítico baseado no conceito de "arranjos produtivos locais" para discutir o processo de construção de competências e de fortalecimento das capacitações inovativas no setor de software, ilustrando esta discussão com informações secundárias relativas à distribuição espacial daquele setor. A quarta seção desenvolve uma análise exploratória sobre a heterogeneidade espacial da indústria, utilizando informações primárias sobre arranjos produtivos dedicados à produção de software, as quais são trabalhadas através de técnicas de estatística multivariada, de modo a 
Jorge Britto / Fabio Stallivieri

identificar diferentes padrões relativos a processos de aprendizado e inovação. Uma última seção sintetiza as principais conclusões do trabalho.

\section{Caracterização do setor}

O software é um produto "intangível” (Gaio, 1992), cujo principal insumo é o conhecimento incorporado em pessoal técnico especializado, cujas criatividade e capacidade intelectual permitem o desenvolvimento de soluções técnicas adequadas a determinados fins. O principal atributo desse "produto" é a sua flexibilidade, incorporada em aplicativos adaptados às necessidades de manipulação de informações de uma grande variedade de atividades econômicas. O dinamismo e o impacto "pervasivo" das inovações geradas pela indústria de software refletem-se em elevadas taxas de nascimento e mortalidade de firmas, bem como numa tendência à volatilidade de lucros e market-shares. Ao mesmo tempo, a heterogeneidade estrutural do setor pode ser associada não apenas à variedade de produtos e serviços gerados, mas também à diversidade das condições competitivas associadas aos seus diversos segmentos.

Essa heterogeneidade implica dificuldades de setorização internas (devido aos distintos segmentos do setor) e externas (relacionadas às tênues fronteiras entre software e outros produtos e serviços associados à indústria de base microeletrônica), refletindo-se na dificuldade para a busca e sistematização de estatísticas rigorosas sobre a indústria, as quais são geralmente escassas e pouco confiáveis. Nesse sentido, é usual o estabelecimento de uma diferenciação entre três segmentos principais ${ }^{4}$ da indústria: produtos (pacote e sob encomenda), serviços (alto valor e baixo valor) e embarcado.

O primeiro segmento (software de pacote) corresponde ao "software propriamente dito", aquele que é destinado aos computadores de pessoas e empresas, envolvendo a venda de uma licença de uso. Os "softwares pacote" são produtos padronizados desenvolvidos a partir de uma estratégia de oferta que visa atender às necessidades de um grande grupo de usuários, envolvendo altos custos de desenvolvimento prévio (acompanhados, em geral, de custos marginais desprezíveis) e pesados investimentos em marketing e atividades promocionais. Nesse caso, o poder da marca e o esforço de divulgação são fatores determinantes de vantagens competitivas, resultando numa estrutura de mercado caracterizada pela presença de grandes corporações (geralmente multinacionais) que dominam os principais segmentos de mercado. Já os "softwares sob encomenda" são desenvolvidos para o atendimento às necessidades exclusivas de um único usuário. $\mathrm{O}$ mercado de software sob encomenda tende a ser bastante diversificado com grandes empresas multinacionais atuando lado a lado com empresas locais. Nesse

(4) Classificação adotada pelo SOFTEX (ver SOFTEX-MIT, 2002). 
segmento, aspectos como reputação e certificação são fundamentais para o desenvolvimento do negócio; porém, o conhecimento ainda permanece como o ativo estratégico principal. A empresa interage com o cliente a cada projeto, com as especificações iniciais do software sendo modificadas durante o processo de desenvolvimento para que o mesmo corresponda exatamente às expectativas $\mathrm{e}$ necessidades do usuário. O "software customizado" localiza-se no meio-termo entre o software pacote e o software sob encomenda, caracterizando-se pelo desenvolvimento de módulos (partes) padronizados que constituem uma solução nuclear, a partir dos quais são feitas adaptações e desenvolvimentos especiais do produto para cada usuário.

Os "serviços de software" correspondem à execução de funções que demandam conhecimentos relacionados à tecnologia de software, dentre as quais se destacam: consultoria, desenvolvimento de aplicativos/componentes, integração, treinamento, suporte técnico e manutenção, entre outros. Esse recorte refere-se aos serviços técnicos agregados ao software, que são fundamentais para que o mesmo desempenhe determinada função de forma eficaz e adaptada às necessidades dos usuários. Segundo Roselino (2006a), é possível estabelecer uma distinção entre serviços de software de baixo e alto valor. Os serviços de software de "baixo valor" são menos densos em termos tecnológicos, envolvendo rotinas ou funções que não dependem de conhecimentos específicos, geralmente relacionados a atividades rotineiras de alimentação de sistemas de informação, como, por exemplo, manutenção e processamento de banco de dados para terceiros. Esses serviços caracterizam-se pela clara separação entre a concepção (centrada no demandante do serviço) e a execução (desenvolvida pela empresa prestadora), demandando o domínio de conhecimentos codificáveis, obteníveis com a formação técnica em programação. No caso desses serviços, a competição normalmente baseia-se no preço e na sinalização de qualidade de processo (envolvendo certificações como CMM e SPICE). Esse segmento é atrativo para micro, pequenas e médias empresas (MPMEs), que operam através de contratos de subcontratação, seguindo a tendência de crescimento das atividades de outsourcing e offshore, decorrente das estratégias das grandes multinacionais, que buscam reduzir os custos com a internacionalização da produção. Em contraste, os serviços de software de "alto valor" são aqueles que incluem etapas mais complexas do desenvolvimento, envolvendo frequentemente conhecimentos específicos de engenharia de software e análise de sistemas, através dos quais se realiza a modelagem da arquitetura de soluções. Os serviços de alto valor referemse à contratação de atividades específicas que exigem um maior nível de conhecimento tecnológico, reforçando a importância da reputação, o que faz com que o mercado seja dominado por grandes empresas multinacionais de consultoria de sistemas (IBM, Accenture, Fujitsu). 
O software embarcado é aquele que vem incorporado em algum produto e não é percebido nem tratado separadamente do equipamento ao qual está integrado. Ele está presente em celulares, aparelhos de DVD, automóveis, bens de capital, etc. Qualquer produto que incorpore módulos eletrônicos de controle carrega em si um software embarcado.

Cada um desses segmentos possui características produtivas, inovativas e competitivas distintas, assim como dinâmicas de aprendizado e estruturas de mercado diversas. É comum a estratificação do mercado em função das características de cada segmento, implicando a coexistência de forças que apontam para sua fragmentação e concentração. No entanto, a tendência mais comum é que as empresas atuem ao mesmo tempo em diversos segmentos. As empresas que desenvolvem pacotes geralmente também atuam oferecendo produtos customizados e agregando serviços aos seus produtos. Ao mesmo tempo, as empresas de software por encomenda também incluem o custo dos softwares pacote de infraestrutura e outras ferramentas utilizadas no desenvolvimento (banco de dados, programas servidores, gerenciadores de rede, segurança, compilador, etc.) em seus custos. Outras empresas operam simultaneamente com hardware e software, comercializando soluções completas de sistemas (incluindo software pacotes ou sob encomenda), incluindo equipamentos e instalação de redes. Em função dessas tendências, torna-se difícil uma segmentação precisa na indústria, o que dificulta a obtenção de estatísticas confiáveis de cada segmento.

Em resumo, o setor de software é uma atividade onde o conhecimento é o fator competitivo crítico, constituindo o principal gerador de vantagens competitivas e de posições monopolistas. Apesar de os segmentos mais rentáveis e padronizados serem dominados por grandes empresas multinacionais, o setor também apresenta grandes oportunidades para MPEs, principalmente na atuação local/regional onde as mesmas podem posicionar-se competitivamente em nichos de mercado, ou ainda estabelecer contratos de parceria e/ou prestação de serviços com grandes empresas. Além disso, a estrutura do setor tende a ser constantemente reconfigurada em função do surgimento de novos produtos e de novos segmentos e nichos de mercado, por intermédio de uma dinâmica comandada pelo processo de inovação tecnológica, que define a amplitude dos ciclos de vida dos produtos, abrindo novas oportunidades para produtores e definindo novas necessidades para os consumidores. Ao mesmo tempo, observa-se um processo de crescente internacionalização de mercados e estratégias, que converte a qualidade e produtividade em fatores determinantes da competitividade empresarial. Cabe ressaltar também que o desenvolvimento de software não é necessariamente uma atividade intensiva em $\mathrm{P} \& \mathrm{D}$, envolvendo mais diretamente a acumulação de conhecimentos, a qualificação técnica do pessoal, a realização de esforços metodológicos e o aprofundamento da interação com clientes mais sofisticados. 


\section{Indústria brasileira de software: panorama geral e esforços inovativos}

Nas últimas décadas, o Brasil desenvolveu uma indústria de software extremamente dinâmica, tornando-se um ator importante no cenário internacional do setor. Mesmo diante do aumento da participação do setor de software no PIB brasileiro, entre 1991 e 2001, salienta-se que uma identificação rigorosa das dimensões do mercado dessa indústria no país é uma tarefa complicada. Dois elementos reforçam essa dificuldade. Em primeiro lugar, as atividades do setor estão usualmente extremamente integradas com outras atividades associadas às tecnologias de informação, de tal modo que algumas das principais empresas atuantes no mercado não têm o desenvolvimento e a produção de software como sua atividade principal. Além disso, o modelo empresarial dos principais atores atuantes no setor é bastante heterogêneo, algumas vezes estando baseado em produtos e outras vezes com a prestação de serviços sendo responsável pela maior parcela das vendas realizadas.

Informações levantadas pelo International Data Group (IDC) para o ano de 2006 estimavam o mercado brasileiro da indústria de software em aproximadamente US\$ 9,09 bilhões, o qual se integrava em um mercado de Tecnologias de Informação (TI) estimado em US\$ 16,2 bilhões (ver Tabela 1). De acordo com essa avaliação, um total de 7.818 empresas exploraria economicamente o setor, das quais 6.091 estariam envolvidas diretamente com a produção e comercialização de softwares (sendo 1.894 empresas dedicadas ao desenvolvimento e produção de software e 4.197 empresas dedicadas à distribuição e revenda de software) e 1.727 empresas dedicadas à prestação de serviços. No ano de 2005, das 1.850 empresas dedicadas ao desenvolvimento e produção de software, 667 poderiam ser classificadas como Microempresas (com menos de 10 empregados), 1.075 como Pequenas Empresas (entre 10-99 empregados), 94 como Médias Empresas (entre 100-500 empregados) e apenas 14 como Grandes Empresas (com mais de 500 empregados).

As informações levantadas pelo IDC para o ano de 2006 possibilitam também uma segmentação das vendas realizadas pela indústria segundo diferentes recortes. Um primeiro recorte possível de ser mencionado refere-se ao tipo de software desenvolvido. Nesse sentido, a Tabela 1 demonstra que $62 \%$ do volume das vendas do setor está associado a software "parametrizável" (ou semicustomizado) que se encontra no meio-termo entre o software pacote "padrão" e o software essencialmente "sob encomenda". Já quando se considera a origem do software (ver Tabela 2), percebe-se que 67,5\% do volume das vendas de softwares comercializados no país está associado a softwares desenvolvidos no exterior, contrastando com a baixa participação de softwares "padrão" desenvolvidos no país (7,7\% das vendas). Já a produção local de software "sob encomenda" é responsável por $23,3 \%$ das vendas do segmento, movimentando 
valores da ordem de US\$ 760 milhões em 2005. No caso do segmento de serviços de software, quase a totalidade $(96,6 \%)$ das vendas está associada ao atendimento do mercado local, sendo ainda bastante restrita a realização de exportações.

Tabela 1

Segmentação do mercado por tipo de software (2006)

\begin{tabular}{l|c|c|c}
\hline Classe & $\begin{array}{c}\text { Volume } \\
\text { (US\$ milhões) }\end{array}$ & $\begin{array}{c}\text { Participação } \\
(\%)\end{array}$ & $\begin{array}{c}\text { Variação } \\
2006 / 2005(\%)\end{array}$ \\
\hline Software Standard & 477 & 22,6 & $+20,0 \%$ \\
\hline Software Parametrizável & 2.023 & 62,1 & $+14,6 \%$ \\
\hline Software Sob Encomenda & 760 & 23,3 & $+36,1 \%$ \\
\hline Subtotal Software & 3.260 & 100,0 & $+19,8 \%$ \\
\hline Subtotal Serviços & 5.830 & 100,0 & $+24,2 \%$ \\
\hline Total Software e Serviços & 9.090 & -- & $+22,6 \%$ \\
\hline
\end{tabular}

Fonte: ABES-IDC (2007).

Tabela 2

Mercado por origem do software/serviço (2006)

\begin{tabular}{l|c|c|c}
\hline Origem & $\begin{array}{c}\text { Volume } \\
\text { (US\$ milhões) }\end{array}$ & $\begin{array}{c}\text { Participação } \\
(\%)\end{array}$ & $\begin{array}{c}\text { Variação } \\
2006 / 2005(\%)\end{array}$ \\
\hline Desenvolvido no Exterior & 2.202 & 67,5 & 14,4 \\
\hline Produção Sob Encomenda & 760 & 23,3 & 36,1 \\
\hline Produção Local Standard & 252 & 7,7 & 24,7 \\
\hline Produção Local Exportação & 52 & 1,5 & 48,5 \\
\hline Subtotal Software & 3.260 & 100,0 & 19,8 \\
\hline Serviços Mercado Local & 5.635 & 96,6 & 23,9 \\
\hline Serviços Exportação & 195 & 3,4 & 24,3 \\
\hline Subtotal Serviços & 5.830 & 100,0 & 22,6 \\
\hline Total Software Serviços & 9.090 & --- & \\
\hline
\end{tabular}

Fonte: ABES-IDC (2007).

O foco principal da indústria brasileira de software é o atendimento ao mercado interno, contrastando com indústrias de outros países nos quais se observa uma nítida orientação para o mercado externo, como Índia, Irlanda, Israel e Canadá. Essa ênfase pode ser explicada em função do crescimento da demanda interna, da disseminação de tecnologias de informação e em razão da própria sofisticação da estrutura produtiva da economia brasileira, não obstante os percalços gerados pela instabilidade macroeconômica e o baixo crescimento das últimas décadas. A origem das empresas brasileiras produtoras de software é bastante diversa, podendo-se observar um processo de acelerada criação de empresas durante a década de 1990, que tendeu a ser substituído por uma tendência à concentração e à especialização das empresas nos últimos anos, devido ao acirramento de pressões competitivas. A estrutura da indústria brasileira de 
software segue um padrão no qual empresas multinacionais tendem a reforçar sua posição nos principais segmentos (horizontais) da indústria, deixando para empresas nacionais a possibilidade de ocupação de segmentos verticais, como no caso do desenvolvimento de soluções que atendam às necessidades do sistema financeiro. De acordo com pesquisa coordenada por Botelho et al. (2003), a maior parte das empresas brasileiras de software surgiu a partir de firmas preexistentes, como "spin-offs" de uma empresa mãe, muitas vezes por iniciativa de antigos empregados que vislumbraram uma oportunidade atrativa de negócios. Três alternativas também assumiram importância como "padrões" de criação de empresas brasileiras produtoras de software. A primeira delas envolve iniciativas individuais (start-ups) de profissionais com talento e criatividade para explorar novas oportunidades advindas do crescimento da indústria. A segunda alternativa compreende um número limitado de "spin-offs" provenientes do meio universitário, geralmente direcionados para segmentos nos quais a experiência anterior de atuação no mercado não parece ser um fator relevante. Finalmente, é possível mencionar a existência de empresas governamentais, geralmente especializadas na manipulação de um grande volume de dados (SERPRO, por exemplo). Em função desse padrão, as empresas locais tenderam a se expandir para várias linhas de negócio simultaneamente, desenvolvendo tanto produtos como serviços de software, gerando uma estrutura fragmentada com grande número de MPEs.

Apesar das possibilidades de sustentar ganhos atrativos a partir dessas estratégias e de persistirem tendências à fragmentação dos mercados, é possível observar uma tendência à concentração industrial do setor nos últimos anos, explicada pelo acirramento de pressões competitivas, pela sofisticação crescente da demanda dos principais mercados consumidores e pelo reforço do processo de internacionalização da indústria. Em consequência, torna-se mais difícil para empresas nacionais sustentarem suas fatias de mercado sem algum tipo de associação com empresas atuantes no exterior. Tais tendências podem ser captadas por informações extraídas de pesquisas anuais sobre o setor realizadas por publicações especializadas. Considerando informações sobre as 200 maiores empresas do setor de informática para o período 2002-2004 apresentadas em levantamento anual realizado pela revista "Exame Informática", observa-se que o número de empresas de software entre as maiores do setor de informática decresceu de 33 para apenas 20 firmas. Por outro lado, o total das vendas realizadas pelas empresas incluídas na listagem elevou-se de US\$ 128 bilhões em 2002 para US\$ 168 bilhões em 2004. Como reflexo do processo de concentração do mercado, as vendas médias por firma incluída na listagem elevaram-se de US\$ 38,9 milhões em 2002 para US\$ 84 milhões em 2004. Observa-se também que, em 2004, apenas seis firmas entre as 20 maiores listadas podiam ser classificadas como empresas domésticas. 
Informações relativas a receitas, pessoal ocupado e nacionalidade das 20 maiores empresas atuantes nos mercados de pacotes de software e serviços de software no Brasil em 2005, levantadas por Tigre e Marques (2007) reforçam essa percepção (ver Tabela 3). No mercado de pacotes de software, as 20 maiores empresas respondiam por $69 \%$ do mercado, sendo que as cinco empresas de capital nacional (Microsiga, Datasul, Consist, RM Sistemas e CSC) não chegam a capturar $20 \%$ das vendas, empregando muito mais em relação ao faturamento do que as demais empresas da lista, devido a sua forte atuação na área de serviços. Em contraste, empresas líderes, como Microsoft e Cisco empregam relativamente pouco e obtêm um elevado faturamento, operando como revendedoras de software importado sem praticamente realizar desenvolvimento local. Nesse mercado, destacam-se também empresas que atuam majoritariamente em outras áreas, mas contam com significativas vendas de licenças de software, como IBM, HP, Cisco, EMC e NCR. No mercado de serviços de software, a participação das 20 maiores empresas é de $52 \%$, sendo pouco mais da metade obtida por firmas de capital nacional. As empresas líderes são multinacionais norte-americanas (IBM, EDS, Unisys, Accenture e HP), que têm forte atuação na área de outsourcing. Entre as oito empresas de capital nacional, a maioria é especializada em serviços, como Politec, ATP, Stefanini e TIVIT.

Tabela 3

Vinte maiores empresas de pacotes e serviços de software, 2005 (em US\$ mil)

\begin{tabular}{|c|c|c|c|c|c|c|c|}
\hline Ordem & Empresa & $\begin{array}{l}\text { País de } \\
\text { Origem }\end{array}$ & $\begin{array}{c}\text { Receita } \\
\text { software } \\
\text { (a) }\end{array}$ & $\begin{array}{c}\text { Receita } \\
\text { Total (b) }\end{array}$ & (a)/(b) & $\begin{array}{l}\text { Pessoal } \\
\text { ocupado } \\
\text { (c) }\end{array}$ & (b)/(c) \\
\hline \multicolumn{8}{|c|}{ Software - Pacotes } \\
\hline 1 & Microsoft & EUA & 519.582 & 525.893 & $98,8 \%$ & 400 & 1.315 \\
\hline 2 & IBM Brasil & EUA & 273.830 & 1.722 .200 & $15,9 \%$ & 12.000 & 144 \\
\hline 3 & Oracle & EUA & 221.048 & 317.142 & $69,7 \%$ & 800 & 396 \\
\hline 4 & Microsiga & Brasil & 136.383 & 161.782 & $84,3 \%$ & 1.779 & 91 \\
\hline 5 & SAP & Alemanha & 122.746 & 167.001 & $73,5 \%$ & 350 & 477 \\
\hline 6 & $\begin{array}{l}\text { Computer } \\
\text { Associates }\end{array}$ & EUA & 98.368 & 112.164 & $87,7 \%$ & 300 & 374 \\
\hline 7 & Datasul & Brasil & 80.617 & 123.645 & $65,2 \%$ & 2.500 & 49 \\
\hline 8 & Consist & Brasil & 79.081 & 154.456 & $51,2 \%$ & 600 & 257 \\
\hline 9 & Symantec & EUA & 56.079 & 69.490 & $80,7 \%$ & 80 & 869 \\
\hline 10 & Hewlett-Packard & EUA & 42.898 & 1.099 .960 & $3,9 \%$ & 1.300 & 846 \\
\hline 11 & RM Sistemas & Brasil & 41.042 & 48.976 & $83,8 \%$ & 1.425 & 34 \\
\hline 12 & Cisco & EUA & 32.399 & 522.561 & $6,2 \%$ & 235 & 2.224 \\
\hline 13 & EMC & EUA & 32.327 & 139.342 & $23,2 \%$ & 250 & 557 \\
\hline 14 & Novell & EUA & 31.636 & 45.002 & $70,3 \%$ & 70 & 643 \\
\hline 15 & $\mathrm{CSC}$ & Brasil & 28.239 & 31.032 & $91,0 \%$ & 150 & 207 \\
\hline 16 & SAS & EUA & 27.397 & 34.203 & $80,1 \%$ & 108 & 317 \\
\hline 17 & Unigraphics & EUA & 27.198 & 38.579 & $70,5 \%$ & 70 & 551 \\
\hline 18 & BMC Software & EUA & 27.077 & 33.762 & $80,2 \%$ & 70 & 482 \\
\hline 19 & Sybase & EUA & 25.651 & 31.473 & $81,5 \%$ & 45 & 699 \\
\hline 20 & NCR & EUA & 20.394 & 95.745 & $21,3 \%$ & 240 & 399 \\
\hline
\end{tabular}


Inovação, cooperação e aprendizado no setor de software no Brasil: análise exploratória baseada no conceito de APLs

Tabela 3 - Continuação

\begin{tabular}{|c|c|c|c|c|c|c|c|}
\hline Ordem & Empresa & $\begin{array}{l}\text { País de } \\
\text { Origem }\end{array}$ & $\begin{array}{c}\text { Receita } \\
\text { software } \\
\text { (a) }\end{array}$ & $\begin{array}{l}\text { Receita } \\
\text { Total (b) }\end{array}$ & (a)/(b) & $\begin{array}{l}\text { Pessoal } \\
\text { ocupado } \\
\text { (c) }\end{array}$ & (b)/(c) \\
\hline \multicolumn{8}{|c|}{ Software - Serviços } \\
\hline 1 & IBM Brasil & EUA & 799.101 & 1.722 .200 & $46,4 \%$ & 12.000 & 144 \\
\hline 2 & EDS & EUA & 500.602 & 500.602 & $100,0 \%$ & 6.800 & 74 \\
\hline 3 & Unisys & EUA & 248.765 & 376.917 & $66,0 \%$ & 2.100 & 179 \\
\hline 4 & Accenture & EUA & 227.619 & 281.012 & $81,0 \%$ & 5.000 & 56 \\
\hline 5 & Hewlett-Packard & EUA & 206.792 & 1.099 .960 & $18,8 \%$ & 1.300 & 846 \\
\hline 6 & Politec & Brasil & 195.705 & 195.705 & $100,0 \%$ & 6.500 & 30 \\
\hline 7 & Xerox & EUA & 174.185 & 688.479 & $25,3 \%$ & 1.600 & 430 \\
\hline 8 & $\begin{array}{l}\text { Diebold } \\
\text { Procomp }\end{array}$ & EUA & 173.998 & 381.574 & $45,6 \%$ & 2.500 & 153 \\
\hline 9 & CPM & Brasil & 168.607 & 255.078 & $66,1 \%$ & 2.600 & 98 \\
\hline 10 & Cobra & Brasil & 160.083 & 253.697 & $63,1 \%$ & 6.800 & 37 \\
\hline 11 & $\begin{array}{l}\text { Telefonica } \\
\text { Empresas }\end{array}$ & Espanha & 120.106 & 407.140 & $29,5 \%$ & 612 & 665 \\
\hline 12 & Itautec & Brasil & 118.318 & 650.100 & $18,2 \%$ & 2.614 & 249 \\
\hline 13 & ATP & Brasil & 115.014 & 115.014 & $100,0 \%$ & 2.100 & 55 \\
\hline 14 & Stefanini & Brasil & 112.000 & 112.000 & $100,0 \%$ & 4.200 & 27 \\
\hline 15 & Procwork & Brasil & 103.951 & 120.313 & $86,4 \%$ & 3.000 & 40 \\
\hline 16 & Siemens & Alemanha & 101.485 & 3.171 .417 & $3,2 \%$ & 7.482 & 424 \\
\hline 17 & TIVIT & Brasil & 98.394 & 98.394 & $100,0 \%$ & 1.300 & 76 \\
\hline 18 & Atos & França & 97.872 & 97.872 & $100,0 \%$ & 1.200 & 82 \\
\hline 19 & Oracle & EUA & 96.094 & 317.142 & $30,3 \%$ & 800 & 396 \\
\hline 20 & Getronics & Holanda & 87.872 & 96.989 & $90,6 \%$ & 700 & 139 \\
\hline
\end{tabular}

Fonte: Série Estudos (2006) apud Tigre e Marques (2007).

De maneira a discutir as características do padrão inovativo predominante no setor de software, comparando-o aos observados em outros ramos de atividade, é útil considerar informações levantadas pela PINTEC-2005 realizada pelo IBGE (2007), a qual incorpora informações sobre o setor de serviços, dentre os quais se incluem "atividades de informática e serviços relacionados", que, por sua vez, são divididas, para fins de apresentação dos resultados, em dois ramos: "consultoria em software" e "outras atividades de informática e serviços relacionados". A Tabela 4 apresenta informações gerais relativas ao desempenho inovativo dessas atividades, avaliado a partir de indicadores extraídos da PINTEC-2005. Com base nessas informações, as seguintes tendências podem ser captadas: (i) uma taxa geral de inovação expressivamente superior à média das atividades avaliadas (57,6\% contra $34,4 \%$, sendo que em "consultoria em software" esse percentual eleva-se a $77,9 \%)$; (ii) taxas mais elevadas de inovação de produto (44,3\% contra $20,6 \%$, a qual se eleva a $67,1 \%$ na atividade de "consultoria em software"), especialmente no que se refere a "produto novo para o mercado nacional" (9,8\% contra $3,6 \%$, 
sendo que em "consultoria em software" esse percentual eleva-se a 21,2\%) ; (iii) taxas de inovação também mais elevadas para "inovações de processo" e "inovação de produto e processo", particularmente no caso de "consultoria em software"; (iv) um percentual de empresas com projetos inovativos no período de cobertura da pesquisa (2003-2005) expressivamente superior à média das atividades investigadas $(27,9 \%$ contra $7,7 \%$ para o conjunto das atividades, com este percentual de empresas se elevando $48,1 \%$ na atividade de "consultoria em software").

As evidências apresentadas indicam que o setor produtor de software apresenta um desempenho inovativo superior à média das atividades econômicas, o que é compatível com as suas características estruturais mencionadas anteriormente. Para viabilizar a introdução de inovações no mercado, faz-se necessária a realização de esforços inovativos consubstanciados em gastos formais em P\&D e outros dispêndios. Esses esforços também podem ser avaliados com base em informações extraídas da PINTEC-2005. A Tabela 5 permite comparar a distribuição dos gastos inovativos nas atividades dedicadas ao desenvolvimento de software com as demais atividades econômicas contempladas na PINTEC. A partir dessa comparação, as seguintes tendências podem ser observadas: (i) uma participação muito maior das atividades internas de $\mathrm{P} \& \mathrm{D}$ no total de gastos inovativos (39,3\% em "atividades de informática" e 49,8\% em "consultoria em software", contra $25,2 \%$ da média da indústria); (ii) uma participação também superior dos esforços em "treinamento" no total de gastos inovativos $(11,7 \%$ em "atividades de informática" e $12 \%$ em "consultoria em software", contra 2,1\% da média da indústria); (iii) uma participação maior das atividades de "aquisição de outros conhecimentos externos" e de "aquisição de software", em comparação com a menor participação de itens relativos à "aquisição de máquinas e equipamentos" e de "projeto industrial". Essas evidências sugerem que, apesar de os esforços inovativos no setor de software não envolverem necessariamente gastos em $\mathrm{P} \& \mathrm{D}$, o dinamismo tecnológico daquelas atividades faz com que esses gastos sejam expressivamente mais elevados do que a média da indústria brasileira. 
Tabela 4

Desempenho inovativo comparado do setor de software - 2005

\begin{tabular}{|c|c|c|c|c|c|c|c|c|}
\hline & Indicador & Total & $\begin{array}{l}\text { Indústrias } \\
\text { extrativas }\end{array}$ & $\begin{array}{l}\text { Indústrias } \\
\text { de } \\
\text { transfor- } \\
\text { mação }\end{array}$ & Serviços & $\begin{array}{l}\text { Atividades } \\
\text { de } \\
\text { informática } \\
\text { e serviços } \\
\text { relacionados }\end{array}$ & $\begin{array}{l}\text { Consul- } \\
\text { toria em } \\
\text { software }\end{array}$ & $\begin{array}{c}\text { Outras } \\
\text { atividades de } \\
\text { informática e } \\
\text { serviços } \\
\text { relacionados }\end{array}$ \\
\hline \multicolumn{2}{|r|}{ Total de empresas } & 95.301 & 1.849 & 89.205 & 4.246 & 3.811 & 1.082 & 2.729 \\
\hline \multicolumn{2}{|c|}{ Empresas Inovadoras } & 32.796 & 427 & 29.951 & 2.418 & 2.197 & 843 & 1.354 \\
\hline \multicolumn{2}{|c|}{ Taxa de inovação (\%) } & $34,4 \%$ & $23,1 \%$ & $33,6 \%$ & $57,0 \%$ & $57,6 \%$ & $77,9 \%$ & $49,6 \%$ \\
\hline \multirow{3}{*}{$\begin{array}{c}\text { Inovação de } \\
\text { Produto }\end{array}$} & Total & $20,6 \%$ & $6,4 \%$ & $19,8 \%$ & $44,4 \%$ & $44,3 \%$ & $67,1 \%$ & $35,3 \%$ \\
\hline & Novo para a empresa & $17,6 \%$ & $5,5 \%$ & $16,9 \%$ & $36,5 \%$ & $36,0 \%$ & $49,9 \%$ & $30,6 \%$ \\
\hline & Novo para o mercado nacional & $3,6 \%$ & $0,9 \%$ & $3,3 \%$ & $10,2 \%$ & $9,8 \%$ & $21,2 \%$ & $5,3 \%$ \\
\hline \multirow{3}{*}{$\begin{array}{c}\text { Inovação de } \\
\text { Processo }\end{array}$} & Total & $27,6 \%$ & $22,3 \%$ & $27,0 \%$ & $41,8 \%$ & $41,7 \%$ & $53,6 \%$ & $37,0 \%$ \\
\hline & Novo para a empresa & $26,0 \%$ & $21,5 \%$ & $25,6 \%$ & $38,1 \%$ & $38,3 \%$ & $48,9 \%$ & $34,1 \%$ \\
\hline & Novo para o mercado nacional & $1,8 \%$ & $1,1 \%$ & $1,7 \%$ & $5,4 \%$ & $4,7 \%$ & $6,4 \%$ & $4,1 \%$ \\
\hline \multicolumn{2}{|c|}{ Inovação de produto e processo } & $13,8 \%$ & $5,6 \%$ & $13,2 \%$ & $29,2 \%$ & $28,4 \%$ & $42,8 \%$ & $22,7 \%$ \\
\hline \multirow{4}{*}{$\begin{array}{c}\text { Com } \\
\text { projetos }\end{array}$} & Total & $7,7 \%$ & $4,8 \%$ & $6,8 \%$ & $28,7 \%$ & $27,9 \%$ & $48,1 \%$ & $19,9 \%$ \\
\hline & Incompletos & $5,1 \%$ & $4,2 \%$ & $4,3 \%$ & $21,2 \%$ & $20,7 \%$ & $31,1 \%$ & $16,6 \%$ \\
\hline & Abandonados & $1,1 \%$ & $0,3 \%$ & $1,1 \%$ & $0,9 \%$ & $1,0 \%$ & $2,5 \%$ & $0,3 \%$ \\
\hline & Ambos & $1,6 \%$ & $0,3 \%$ & $1,4 \%$ & $6,7 \%$ & $6,2 \%$ & $14,5 \%$ & $2,9 \%$ \\
\hline
\end{tabular}

Fonte: Elaboração própria a partir da PINTEC - 2005 (2007). 
Tabela 5

Esforço inovativo comparado do setor de software - 2005

\begin{tabular}{|c|c|c|c|c|c|c|c|}
\hline Esforços inovativos & Total & $\begin{array}{l}\text { Indústrias } \\
\text { extrativas }\end{array}$ & $\begin{array}{l}\text { Indústrias de } \\
\text { transformação }\end{array}$ & Serviços & $\begin{array}{l}\text { Atividades de } \\
\text { informática e } \\
\text { serviços } \\
\text { relacionados }\end{array}$ & $\begin{array}{l}\text { Consul- } \\
\text { toria em } \\
\text { software }\end{array}$ & $\begin{array}{l}\text { Outras } \\
\text { atividades de } \\
\text { informática e } \\
\text { serviços } \\
\text { relacionados }\end{array}$ \\
\hline Receita líquida de vendas (1.000 R\$) & 1.357.329.945 & 37.854 .126 & 1.202 .698 .981 & 116.776 .838 & 26.650 .007 & 1.570 .1059 & 1.0948 .948 \\
\hline Gastos com Inovação & 41.289 .212 & 681.286 & 33.724 .694 & 6.883 .232 & 1.576 .744 & 864.511 & 712.233 \\
\hline \multicolumn{8}{|c|}{ \% Gastos com inovação - total } \\
\hline Atividades internas de Pesquisa e Desenvolvimento & $25,16 \%$ & $11,39 \%$ & $20,86 \%$ & $47,57 \%$ & $39,33 \%$ & $49,84 \%$ & $26,56 \%$ \\
\hline Aquisição externa de Pesquisa e Desenvolvimento & $2,91 \%$ & $1,74 \%$ & $2,80 \%$ & $3,56 \%$ & $2,35 \%$ & $1,66 \%$ & $3,18 \%$ \\
\hline Aquisição de outros conhecimentos externos & $4,61 \%$ & $3,15 \%$ & $4,76 \%$ & $4,03 \%$ & $7,22 \%$ & $6,13 \%$ & $8,53 \%$ \\
\hline Aquisição de software & $3,81 \%$ & $1,12 \%$ & $1,97 \%$ & $13,09 \%$ & $7,14 \%$ & $4,42 \%$ & $10,45 \%$ \\
\hline Aquisição de máquinas e equipamentos & $42,90 \%$ & $76,80 \%$ & $47,81 \%$ & $15,53 \%$ & $21,42 \%$ & $14,16 \%$ & $30,23 \%$ \\
\hline Treinamento & $2,06 \%$ & $1,27 \%$ & $1,86 \%$ & $3,10 \%$ & $11,68 \%$ & $11,92 \%$ & $11,38 \%$ \\
\hline Introdução das inovações tecnológicas no mercado & $7,49 \%$ & $0,97 \%$ & $6,89 \%$ & $11,08 \%$ & $7,98 \%$ & $7,92 \%$ & $8,05 \%$ \\
\hline Projeto industrial e outras preparações técnicas & $11,05 \%$ & $3,56 \%$ & $13,04 \%$ & $2,04 \%$ & $2,89 \%$ & $3,95 \%$ & $1,61 \%$ \\
\hline \multicolumn{8}{|c|}{ \% Gastos com inovação em relação à receita } \\
\hline Participação de Gastos na Receita (\%) - Total & $3,04 \%$ & $1,80 \%$ & $2,80 \%$ & $5,89 \%$ & $5,92 \%$ & $5,51 \%$ & $6,51 \%$ \\
\hline Atividades internas de Pesquisa e Desenvolvimento & $0,77 \%$ & $0,20 \%$ & $0,58 \%$ & $2,80 \%$ & $2,33 \%$ & $2,74 \%$ & $1,73 \%$ \\
\hline Aquisição externa de Pesquisa e Desenvolvimento & $0,09 \%$ & $0,03 \%$ & $0,08 \%$ & $0,21 \%$ & $0,14 \%$ & $0,09 \%$ & $0,21 \%$ \\
\hline Aquisição de outros conhecimentos externos & $0,14 \%$ & $0,06 \%$ & $0,13 \%$ & $0,24 \%$ & $0,43 \%$ & $0,34 \%$ & $0,56 \%$ \\
\hline Aquisição de software & $0,12 \%$ & $0,02 \%$ & $0,06 \%$ & $0,77 \%$ & $0,42 \%$ & $0,24 \%$ & $0,68 \%$ \\
\hline Aquisição de máquinas e equipamentos & $1,31 \%$ & $1,38 \%$ & $1,34 \%$ & $0,92 \%$ & $1,27 \%$ & $0,78 \%$ & $1,97 \%$ \\
\hline Treinamento & $0,06 \%$ & $0,02 \%$ & $0,05 \%$ & $0,18 \%$ & $0,69 \%$ & $0,66 \%$ & $0,74 \%$ \\
\hline Introdução das inovações tecnológicas no mercado & $0,23 \%$ & $0,02 \%$ & $0,19 \%$ & $0,65 \%$ & $0,47 \%$ & $0,44 \%$ & $0,52 \%$ \\
\hline Projeto industrial e outras preparações técnicas & $0,34 \%$ & $0,06 \%$ & $0,37 \%$ & $0,12 \%$ & $0,17 \%$ & $0,22 \%$ & $0,10 \%$ \\
\hline
\end{tabular}

Fonte: Elaboração própria a partir da PINTEC - 2005 (2007). 
Com base nas informações apresentadas na Tabela 5 é possível avaliar também a "intensidade" dos esforços tecnológicos em relação à receita das empresas atuantes no setor. Em especial, observa-se que essa intensidade é expressivamente mais elevada nas "atividades de informática e serviços relacionados" $(5,9 \%)$ do que no conjunto de atividades investigadas pela PINTEC2005 (3,0\%). Desagregando-se essa intensidade pelos diferentes itens dos esforços inovativos, verifica-se que a mesma é particularmente mais elevada nos casos de atividades de $\mathrm{P} \& \mathrm{D}(2,33 \%$ contra $0,77 \%)$, aquisição de conhecimentos externos $(0,43 \%$ contra $0,14 \%)$, aquisição de software $(0,42 \%$ contra $0,12 \%)$ e treinamento $(0,69 \%$ contra $0,06 \%)$.

Para superar os desafios competitivos enfrentados por empresas domésticas produtoras de software é importante incrementar os esforços inovativos realizados pela indústria. Nesse sentido, outras evidências complementam as informações da PINTEC. Pesquisa realizada pelo MCT-Sepin ${ }^{5}$ em 2001, com uma amostra de 446 firmas, indicou que apenas 16,5\% das empresas utilizavam o registro de direitos de propriedade (copyright rights) de forma sistemática e $6,5 \%$ o faziam de forma ocasional. Além disso, essa pesquisa demonstrou que as empresas investiam em média $14 \%$ de suas receitas, sendo aproximadamente 7,5\% desses investimentos associados a gastos de P\&D. No que concerne à qualificação técnica, apenas $18 \%$ das firmas possuíam padrões de certificação da qualidade equivalentes aos padrões CMM ou SPICE e que 50\% dos empregados apresentavam nível superior, com aproximadamente 2,5 empregados pós-graduados por firma. Para reforçar a posição competitiva das empresas no mercado, padrões superiores de qualidade se tornam imprescindíveis, através do atendimento a normas e especificações que se refletem na certificação formal dos produtores segundo padrões internacionais. No setor de software, é usual que essa certificação utilize como referência os padrões $\mathrm{CMM}^{6}{ }^{6}$ podendo-se observar que um número restrito de empresas brasileiras apresenta níveis superiores de certificação segundo esse padrão (níveis CMM 3 ou superior). Por um lado, isso reflete uma ênfase na busca pelas empresas brasileiras de certificação segundo o padrão ISO 9000, em detrimento do padrão CMM. Por outro lado, essa certificação tende a ficar limitada a produtos, com as empresas que atuam na

(5) MCT - Ministério da Ciência e Tecnologia; Sepin - Secretaria de Política de Informática.

(6) O CMM - Capability Maturity Model é um modelo de certificação desenvolvido pelo Software Engineering Institute (SEI) da Carnegie Mellon University para avaliar a maturidade do processo de desenvolvimento de software em uma empresa. Esse modelo define cinco níveis de maturidade: inicial; repetitivo; definido; gerenciado; otimizado. O padrão CMMI - Capability Maturity Model Integration foi criado como uma evolução do CMM, o qual foi integrado com dois outros modelos para avaliar a performance no desenvolvimento de software - o modelo SECM - System Engineering Capability Model e o modelo IPD-CMM - Integrated Product Development CMM. 
prestação de serviços optando por desenvolver seus próprios padrões, sem recorrer à certificação formal, o que limita as possibilidades de expansão para mercados internacionais. Informações mais recentes, no entanto, apontam para uma mudança progressiva desse quadro. Segundo avaliação do MCT realizada com o apoio da Integrated System Diagnostics - ISD-Brasil, uma subsidiária da American ISD Inc que está autorizada a realizar avaliações oficiais acerca do atendimento de condições CMN por empresas brasileiras, existiam, em agosto de 2006, 49 empresas em processo de obtenção de certificação CMM e 21 empresas em processo de obtenção de certificação CMMI no Brasil. Dentre elas, apenas um número limitado de empresas já haviam obtido uma certificação CMMI nível 5 (EDS, BRQ Soluções em Informática; IBM, Stefanini e Tata Consultancy Services do Brasil). Como resultado desse processo, o Brasil ocupava a $14^{\underline{a}}$ posição em termos da certificação CMM e a $11^{\underline{a}}$ posição em certificação CMMI em setembro de 2005, de acordo com a avaliação periódica realizada pela ISD Inc. Esse nível ainda era expressivamente inferior ao observado em países que operam como plataformas exportadoras de software e de serviços de outsourcing como a Índia (com 422 empresas certificadas em 2005), China (354 empresas certificadas) e Canadá (85 empresas certificadas).

No tocante ao desempenho exportador da indústria de software, cabe ressaltar, de início, as dificuldades inerentes à mensuração desses valores. ${ }^{7}$ Pesquisa realizada pela SOFTEX e pelo Massachusetts Institute of Technology (MIT) em 2002 revelou que apenas 1,5\% do faturamento do setor no país estava relacionado à exportação, gerando um desequilíbrio na balança comercial de quase $\mathrm{R} \$ 1$ bilhão. Informações mais recentes do Banco Central indicavam que, em 2004, os 20 maiores exportadores de software eram responsáveis por exportações da ordem de US\$ 230 milhões (98\% do total). Informações sistematizadas pelo IDC (2006) relativas às exportações realizadas em 2006 apontavam para exportações de software da ordem de US\$ 247 milhões, sendo US\$ 52 milhões em produtos e US\$ 195 milhões em serviços. No entanto, as evidências sugerem que aproximadamente $85 \%$ das exportações de TI fazem parte de um mercado "cinza", sendo dificilmente contabilizadas, em particular no caso de operações envolvendo empresas multinacionais. Identifica-se, porém, uma diversidade de MPMEs produtoras de software com excelência em alguns nichos e com uma cultura exportadora em consolidação (como, por exemplo, no caso de jogos digitais).

O desempenho exportador da indústria brasileira de software é desproporcionalmente pequeno em relação às dimensões gerais da atividade doméstica, especialmente quando contrastados com os valores advindos de

(7) Esse produto/serviço pode ser transacionado a partir de diversos canais de comercialização, como, por exemplo, compra de software por meio da Internet. Assim, o comércio exterior de software deixa poucos registros nos dados oficias da SECEX devido ao seu caráter intangível. 
indústrias de proporções semelhantes situadas em países não centrais (como nos casos de Índia, Irlanda, Israel, e mesmo China). Nesse sentido, a existência de um programa nacional de exportação de software (no qual se destacam as ações do SOFTEX $^{8}$ ) criado há mais de uma década foi incapaz de produzir resultados satisfatórios. Apesar desse quadro, existem sinais de que mudanças podem vir a ocorrer. De acordo com dados coletados pela BRASSCOM (Associação Brasileira de Firmas Exportadoras de Softwares e Serviços), 300 empresas de software demonstraram interesse em se tornar exportadoras. Segundo informações contabilizadas por essa associação, em 2004, 71 empresas exportaram produtos e serviços de software, gerando um montante de exportações da ordem de aproximadamente US\$ 235 milhões, dos quais US\$ 110 milhões foram provenientes de produtos de software e US\$ 125 milhões de serviços e outsourcing. O total das vendas das empresas exportadoras de software atingiu aproximadamente US\$ 1,5 bilhão naquele ano, com as exportações de software correspondendo a $15 \%$ desse total. Segundo informações da BRASSCOM, as expectativas dessas empresas eram de elevar suas exportações para algo em torno de US\$ 470 milhões em 2009. A BRASSCOM foi criada como uma cópia da indiana Nasscom, orientando-se à prestação de serviços de consultoria associados à melhoria da qualidade dos produtos e à intensificação dos esforços de marketing. Destaca-se também a formação de consórcios como o Núcleo Brasileiro de Exportação de Tecnologia (Next), que reúne 15 empresas nacionais de serviços e produtos de software, uma força de trabalho de 11 mil colaboradores e faturamento anual de $\mathrm{R} \$ 1,19$ bilhão. Cabe mencionar também a criação do Projeto Setorial Integrado para Exportação de Software e Serviços Correlatos (PSI-SW), envolvendo APEX e SOFTEX, e o fortalecimento do apoio do BNDES ao setor através do programa PROSOFT, cujo valor das operações atingia aproximadamente $\mathrm{R} \$ 800$ milhões em maio de 2007 (sendo $\mathrm{R} \$ 218$ milhões alocados no PROSOFT - Exportação).

(8) O Programa Sociedade para Promoção da Excelência do Software Brasileiro (SOFTEX) foi criado inicialmente com foco no apoio à exportação de software desenvolvido no país, buscando contribuir ativamente para a capacitação, criação de novas empresas de Software no país e no apoio à comercialização do software brasileiro nos mercados interno e externo. O objetivo era transformar o Brasil em um centro de excelência na produção e exportação de software, funcionando como um tripé: empresas, governo e academia, prevendo-se a capacitação técnico-empresarial de mais de mil empresas e a geração de 50 mil postos de trabalho de alta qualidade. O Programa não visava apenas à exportação, mas sim ao crescimento dessas empresas para atender com qualidade ao mercado interno; a exportação era uma consequência do aumento de capacitação das firmas brasileiras. Posteriormente, o programa foi reorientado para a formação de 22 núcleos regionais em 12 estados. Sua atuação para promoção das atividades de software inclui apoio técnico, gerencial e marketing, implantação de laboratórios para desenvolvimento e pesquisa de software, incentivo à cooperação e interação, parcerias com universidades e instituições de pesquisa locais e criação de incubadoras para novas empresas. 
Jorge Britto / Fabio Stallivieri

\section{Distribuição espacial e a presença de arranjos produtivos na indústria}

\subsection{Referencial analítico: o conceito de arranjos produtivos}

A utilização de um recorte analítico baseado no conceito de "Arranjos Produtivos Locais" parte da hipótese de que a aglomeração espacial de atividades econômicas em determinada região proporciona o acúmulo de conhecimentos especializados, boa parte dos quais de natureza tácita e específica, que reforçam as capacitações produtivas, técnicas e tecnológicas dos agentes locais. O processo cumulativo de criação de conhecimentos e capacitações em escala local dá origem a sistemas complexos que evoluem de acordo com os estímulos do ambiente competitivo, podendo apresentar graus variados de desenvolvimento, em termos da integração das cadeias produtivas, da articulação e interação entre agentes produtivos e instituições locais, e da consolidação de capacidades sistêmicas para a inovação. A complexidade estrutural e institucional é uma característica inerente a esses arranjos, na medida em que os mesmos admitem "variadas caracterizações conforme sua história, evolução, organização institucional, contextos sociais e culturais nos quais se inserem, estrutura produtiva, organização industrial, formas de governança, logística, associativismo, cooperação entre agentes, formas de aprendizado e grau de disseminação do conhecimento especializado local" (Suzigan et al., 2004, p. 2).

Em função da complexidade desse objeto, é natural que os esforços de exploração do seu potencial analítico se desdobrem em múltiplas direções. Uma primeira direção - motivo de alguma controvérsia na vasta literatura elaborada recentemente no Brasil com base naquele conceito - refere-se à busca de uma maior precisão no detalhamento de aspectos fundamentais para a caracterização da estrutura e das formas de operação desses arranjos. Cassiolato e Lastres (2003), por exemplo, destacam o papel central da inovação e do aprendizado interativo como fatores de competitividade sustentada nesses arranjos, argumentando que a articulação entre empresas (e com outras instituições locais) possibilita a ampliação da capacidade endógena de geração, difusão e utilização de novos conhecimentos, num processo que transcende a firma individual e depende da contínua interação entre os agentes locais. Nessa perspectiva, ressalta-se a importância dos processos de aprendizado, cooperação e inovação, referentes a espaços geográficos específicos, os quais geram um potencial de fortalecimento da competitividade e do desenvolvimento local. A importância atribuída à consolidação de práticas cooperativas e aos processos de aprendizado por interação está vinculada à visão sistêmica do processo de inovação.

Suzigan et al. (2004) exploram analiticamente o conceito a partir de uma ênfase na capacidade de geração de economias externas e no impacto das mesmas sobre a dinâmica setorial e espacial. Destacam, nesse sentido, a distinção entre 
economias externas incidentais ou deliberadamente criadas, as quais fortalecem a competitividade das empresas inseridas nesses arranjos. As economias externas incidentais estariam relacionadas a diversos fatores, como a presença de mão de obra especializada, de fornecedores especializados, de matéria-prima, componentes e serviços na região, bem como à tendência de disseminação de conhecimentos, habilidades e informações concernentes ao ramo de atividade entre os produtores locais. As economias externas deliberadas estariam relacionadas a ações conjuntas que reforçam a competitividade dos agentes locais - envolvendo a compra de matérias-primas, a promoção da capacitação gerencial e profissional, atividades de exportação, a contratação de serviços especializados e a estruturação de cooperativas de crédito, dentre outros aspectos - gerando uma "eficiência coletiva" (Schmitz; Nadvi, 1999) que reforça a competitividade das empresas integradas a tais arranjos. Outra linha de desenvolvimento analítico importante está presente nos trabalhos de pesquisadores do Cedeplar-UFMG (Santos; Crocco; Lemos, 2002; Crocco et al., 2003; Crocco et al., 2006). Essa abordagem ressalta que o processo de fortalecimento de capacitações produtivas e inovativas, a complexidade do ambiente institucional e os estímulos provenientes do entorno social local assumem características específicas em contextos que, grosso modo, podem ser caracterizados como "periféricos". Nesses contextos, existiriam restrições objetivas ao pleno desenvolvimento desses arranjos, que podem criar obstáculos à consolidação de trajetórias virtuosas de incremento das capacitações inovativas.

Além da discussão dos elementos característicos da estrutura e das formas de operação desses arranjos, outras linhas de desenvolvimento analítico importantes no desenvolvimento de um programa de pesquisa assentado naquele tipo de referencial envolvem os seguintes aspectos:

(1) O desenvolvimento de metodologias específicas para identificar e delimitar geograficamente a presença desses arranjos, através da utilização de informações secundárias, da construção de indicadores e do eventual tratamento dos mesmos através de técnicas estatísticas (Britto, 2003; Crocco et al., 2003; Crocco et al., 2006; Suzigan et al., 2003; Suzigan, 2006);

(2) A construção de tipologias acerca dos padrões de organização desses arranjos, seja considerando os impactos gerados sobre a dinâmica do setor e da região nos quais se inserem (Suzigan et al., 2004), seja considerando aspectos especificamente relacionados à conformação das estruturas de governança subjacentes (Suzigan; Garcia; Furtado, 2007; Campos; Vargas, 2003), ou ainda combinando essa conformação com aspectos relativos à importância da territorialidade (Cassiolato; Szapiro, 2003); 
Jorge Britto / Fabio Stallivieri

(3) A identificação de orientações para políticas públicas que tenham como objetivo a formação, a consolidação e o upgrade produtivo e tecnológico desses arranjos, considerando o estágio de desenvolvimento dos mesmos e seus impactos sobre a dinâmica regional e setorial (Suzigan et al., 2004 e 2007), as formas de governança prevalecentes em cada situação (Cassiolato; Szapiro, 2003; Campos, 2004) ou os princípios gerais que devem nortear tais políticas (Suzigan, 2000; Cassiolato; Villashi; Campos, 2003; Britto, 2005).

Outro procedimento importante para o avanço desse programa de pesquisa refere-se à realização de análises comparativas de diferentes arranjos, com base num instrumental analítico e metodológico comum, visando captar características específicas das formas de operação dos mesmos, que condicionam suas trajetórias evolutivas e as perspectivas de reforço das capacitações inovativas (Britto et al., 2007). Nesse sentido, verifica-se que, não obstante a percepção sobre a importância crescente que assumem as práticas cooperativas e o aprendizado localizado nesses arranjos, ainda existem lacunas consideráveis na análise tanto das formas de mensuração desses processos como do seu impacto efetivo sobre o desempenho inovativo de empresas articuladas em torno dessas estruturas (Stallivieri; Campos; Britto, 2007).

A possibilidade de realização de estudos comparativos entre diferentes aglomerações parece ser um caminho fértil de investigação, na medida em que permite captar e contrastar particularidades relacionadas à dinâmica de aprendizado, cooperação e inovação em cada situação. A análise desenvolvida a seguir sugere que é possível integrar um conjunto de informações primárias sobre esses arranjos coletadas em pesquisas de campo, de maneira a ressaltar algumas "dimensões" fundamentais dos processos de aprendizado e cooperação característicos desses arranjos, bem como os possíveis desdobramentos em termos do fortalecimento das capacitações inovativas e da competitividade dos agentes a eles integrados. Em especial, dado o caráter ainda incipiente da consolidação desses arranjos no Brasil, é importante avaliar em que medida processos virtuosos de fortalecimento de capacitações inovativas se disseminam entre as empresas integradas a esses arranjos ou se, pelo contrário, há uma tendência de reforço da heterogeneidade entre as mesmas.

Com esse intuito, procura-se desenvolver um conjunto de indicadores relacionados ao esforço tecnológico, à aprendizagem tecnológica, à cooperação e ao desempenho tecnológico, para as firmas inseridas em arranjos produtivos locais associados ao setor de software, a partir de um questionário estruturado, utilizado tanto no programa "MPEs em Arranjos Produtivos Locais no Brasil", realizado 
pela UFSC e o SEBRAE-NA, quanto em pesquisas da RedeSist. ${ }^{9}$ Utiliza-se um conjunto selecionado de perguntas que constam do questionário aplicado nas empresas, procurando-se transformar atributos qualitativos, tais como a importância atribuída pela empresa a determinado evento, em quantitativos. Esse tipo de procedimento permite obter evidências acerca da "dinâmica interna" subjacente a cada arranjo, através do detalhamento do conteúdo das informações transmitidas, dos padrões de aprendizado e das formas de cooperação produtiva e tecnológica predominantes em cada situação. Uma análise consistente dessa "dinâmica interna" requer também um esforço particular para avaliar os impactos das práticas cooperativas em termos do desempenho inovativo e competitivo dos agentes integrados aos arranjos investigados.

\subsection{Distribuição espacial da indústria de software: evidências da presença de arranjos produtivos locais}

De modo a subsidiar a análise de arranjos produtivos locais no setor de software, é importante considerar um panorama geral da distribuição espacial daquela indústria no país. A indústria brasileira de software encontra-se concentrada nas regiões mais desenvolvidas do país. Considerando um recorte espacial pelas diferentes unidades da federação, percebe-se, a partir de informações da Tabela 6, que as quatro UFs com maior receita operacional líquida total concentram $87 \%$ da receita nacional dessas atividades, sendo que o estado de São Paulo individualmente responde por quase metade desse valor. Cabe destacar também a importância do Distrito Federal, que possui apenas cerca de $2 \%$ das empresas do país, mas responde por cerca de $8 \%$ da receita operacional líquida total relacionada a essas atividades, concentrando empresas públicas de maior porte. Quando se consideram indicadores relativos ao tamanho médio das empresas e receita por empregado verifica-se que existem diferenças significativas entre os estados. Nesse sentido, o maior porte das empresas no Distrito Federal não é acompanhado por um maior valor da receita por empregado (proxis da produtividade do trabalho), que é expressivamente inferior à observada no Rio de Janeiro e São Paulo. Por outro lado, informações levantadas em estudo realizado pelo SOFTEX (2002) apontavam para a existência de diferenciais salariais bastante significativos para diversos tipos de profissionais envolvidos com a indústria de software nas diferentes regiões do país.

(9) A Rede de Sistemas Produtivos e Inovativos Locais (RedeSist) é uma rede de pesquisa interdisciplinar, sediada no Instituto de Economia da Universidade Federal do Rio de Janeiro e que conta com a participação de várias universidades e institutos de pesquisa no Brasil, além de parcerias com instituições do exterior (Cassiolato; Lastres, 2003).

Economia e Sociedade, Campinas, v. 19, n. 2 (39), p. 315-358, ago. 2010. 
Jorge Britto / Fabio Stallivieri

Tabela 6

Distribuição das empresas e do pessoal ocupado por Unidades da Federação (2002)

\begin{tabular}{c|r|r|r|r|r|r|r|r}
\hline $\begin{array}{c}\text { Unidade } \\
\text { da } \\
\text { Federação }\end{array}$ & $\begin{array}{c}\text { Número } \\
\text { de } \\
\text { Empresas }\end{array}$ & \multicolumn{1}{|c|}{$\%$} & $\begin{array}{c}\text { Receita } \\
\text { Líquida } \\
\text { Total }(\mathrm{R} \$\end{array}$ & $\%$ & $\begin{array}{c}\text { Pessoal } \\
\text { Ocupado } \\
\text { Total }\end{array}$ & $\%$ & $\begin{array}{c}\text { Porte } \\
\text { (empregado } \\
\text { por firma) }\end{array}$ & $\begin{array}{c}\text { Receita } \\
\text { por } \\
\text { empregado }\end{array}$ \\
\hline SP & 19.845 & $48,1 \%$ & 9.279 .701 .977 & $46,1 \%$ & 95.059 & $37,5 \%$ & 4,79 & 97.620 \\
\hline RJ & 5.400 & $13,1 \%$ & 5.954 .684 .491 & $29,6 \%$ & 43.131 & $17,0 \%$ & 7,99 & 138.060 \\
\hline DF & 890 & $2,2 \%$ & 1.510 .053 .083 & $7,5 \%$ & 23.543 & $9,3 \%$ & 26,45 & 64.140 \\
\hline MG & 3.604 & $8,7 \%$ & 646.269 .812 & $3,2 \%$ & 14.540 & $5,7 \%$ & 4,03 & 44.448 \\
\hline RS & 2.745 & $6,7 \%$ & 636.922 .603 & $3,2 \%$ & 13.579 & $5,4 \%$ & 4,95 & 46.905 \\
\hline SC & 2.036 & $4,9 \%$ & 466.033 .380 & $2,3 \%$ & 9.092 & $3,6 \%$ & 4,47 & 51.258 \\
\hline GO & 546 & $1,3 \%$ & 410.920 .283 & $2,0 \%$ & 8.431 & $3,3 \%$ & 15,44 & 48.739 \\
\hline PR & 1.871 & $4,5 \%$ & 325.712 .072 & $1,6 \%$ & 11.167 & $4,4 \%$ & 5,97 & 29.167 \\
\hline BA & 928 & $2,2 \%$ & 229.522 .154 & $1,1 \%$ & 6.146 & $2,4 \%$ & 6,62 & 37.345 \\
\hline PE & 834 & $2,0 \%$ & 182.970 .399 & $0,9 \%$ & 4.385 & $1,7 \%$ & 5,26 & 41.726 \\
\hline Outros & 2.559 & $6,2 \%$ & 466.566 .785 & $2,3 \%$ & 24.092 & $9,5 \%$ & 9,41 & 19.366 \\
\hline Total & 41.258 & $100,0 \%$ & 20.109 .357 .039 & $100,0 \%$ & 253.165 & $100,0 \%$ & 6,14 & 79.432 \\
\hline
\end{tabular}

Fonte: Roselino (2006b).

Na discussão sobre a distribuição espacial da indústria brasileira produtora de software deve-se considerar que a proximidade territorial constitui um importante fator indutor da aceleração de mecanismos de aprendizado e de fortalecimento da competitividade empresarial. Essa proximidade espacial é também importante na medida em que tende a induzir o surgimento de instituições e firmas com competências complementares, a partir dos quais podem ser reforçadas práticas interativas - nesse caso, essencialmente vinculadas a fluxos intangíveis de informações e conhecimentos - capazes de sustentar o dinamismo inovativo e a competitividade. Apesar dessa tendência geral, há indícios de que a possibilidade de geração desses ganhos encontra-se condicionada pelo padrão de especialização produtiva e pelas características específicas das instituições e outros agentes locais. No âmbito específico da indústria de software, a preocupação em formatar políticas de apoio ao setor que considerem a importância da dimensão espacial refletiu-se na criação de estímulos à consolidação de "polos" tecnológicos direcionados para aquelas atividades, geralmente baseados em algum processo de incubação de empresas. A ênfase na concessão de estímulos à criação desses polos está presente tanto em ações do Programa SOFTEX como de organismos de governo como FINEP e MDIC, resultando na criação de 21 núcleos espacialmente dispersos pelo território nacional.

Partindo desse tipo de recorte, é possível utilizar alguns procedimentos para identificar e analisar aglomerações produtivas espacialmente localizadas no setor de software, as quais constituem evidências preliminares acerca da presença de arranjos produtivos nessas atividades. A análise desenvolvida a seguir utiliza como fonte básica de informações os dados da Relação Anual de Informações Sociais do Ministério do Trabalho e Emprego (RAIS-MTE) para o ano de 2006, 
contemplando os trabalhadores formais registrados, o número de estabelecimentos presentes nos diversos ramos de atividades e o valor total das remunerações geradas. A metodologia desenvolvida utiliza como referência espacial básica a microrregião econômica (definida pelo IBGE) na qual se encontram localizadas as principais atividades produtoras de software (4 dígitos / CNAE 2.0): (1) Classe 62015 - Desenvolvimento de programas de computador sob encomenda; (2) Classe 62023 - Desenvolvimento e licenciamento de programas de computador customizáveis; (3) Classe 62031 - Desenvolvimento e licenciamento de programas de computador não customizáveis. O objetivo básico da análise é mensurar o processo de aglomeração de atividades produtoras de software no espaço, qualificando essa aglomeração em função do porte das atividades e, em relação ao total do emprego e remunerações no total daquelas atividades.

Um total de 30 aglomerações (microrregiões) com mais de $0,3 \%$ do emprego total gerado em atividades produtoras de software em 2006 foi selecionado, cujas principais características são apresentadas na Tabela 7. Essas aglomerações eram responsáveis por aproximadamente $93 \%$ do emprego total das atividades de desenvolvimento de software contabilizado pela RAIS, gerando 51.292 empregos, dos quais $28.449(55,5 \%)$ no segmento de programas de computador sob encomenda; $6.613(12,9 \%)$ no segmento de programas de computador customizáveis e $16.230(31,6 \%)$ no segmento de programas de computador não customizáveis. Nessas aglomerações, operavam 2.281 estabelecimentos, os quais pagavam um salário mensal em torno de $\mathrm{R} \$ 2.171$ para seus empregados em 2006. Comparadas com o conjunto das atividades econômicas locais, as atividades associadas ao desenvolvimento de software são particularmente bem remuneradas, com os salários sendo aproximadamente 54\% mais elevados que os do conjunto das atividades produtivas daquelas regiões. $\mathrm{O}$ tamanho médio das firmas produtoras de software nas aglomerações atingia 19 empregados e para o conjunto das aglomerações selecionadas o valor do índice de "especialização relativa"10 das mesmas em atividades produtoras de software atingia 2,01. Esse valor pode ser explicado em função da presença de aglomerações em microrregiões associadas às capitais de estado que conformam regiões metropolitanas com uma base produtiva diversificada.

(10) Este índice de especialização relativa corresponde a um Quociente Locacional (QL) referente ao emprego, que permite identificar a existência de aglomerações especializadas em uma determinada atividade econômica. Adotando-se como base o total de empregados registrados no setor de software (EMPSOFT) em cada microrregião informado pela RAIS, o cálculo do índice é feito segundo a fórmula: $Q L=$ (EMPSOFT na microrregião / EMP total microrregião j) / (EMPSOFT no país / EMP total do país). Quando o QL é maior do que 1, há evidências de que a especialização da microrregião no setor de software é superior à especialização do conjunto do Brasil naquelas atividades.

Economia e Sociedade, Campinas, v. 19, n. 2 (39), p. 315-358, ago. 2010. 
Tabela 7

Aglomerações (microrregiões CNAE) especializadas no desenvolvimento de software - 2006

\begin{tabular}{|c|c|c|c|c|c|c|c|c|c|c|}
\hline Microrregiões & $\begin{array}{l}\text { Estabele- } \\
\text { cimentos }\end{array}$ & Empregos & $\begin{array}{c}\text { Tama- } \\
\text { nho } \\
\text { Médio }\end{array}$ & $\begin{array}{c}\text { Remune- } \\
\text { ração } \\
\text { Média }\end{array}$ & $\begin{array}{c}\% \text { no } \\
\text { Emprego } \\
\text { setorial }\end{array}$ & $\begin{array}{c}\% \text { do } \\
\text { setor no } \\
\text { emprego } \\
\text { da } \\
\text { Micror- } \\
\text { região }\end{array}$ & $\begin{array}{l}\text { Índice } \\
\text { de } \\
\text { especia- } \\
\text { lização } \\
\text { relativa } \\
\text { (QL) }\end{array}$ & $\begin{array}{c}\% \\
\text { Emprego - } \\
\text { Programas } \\
\text { sob } \\
\text { encomenda }\end{array}$ & $\begin{array}{c}\% \\
\text { Emprego - } \\
\text { Programas } \\
\text { customi- } \\
\text { záveis }\end{array}$ & $\begin{array}{c}\% \\
\text { Emprego - } \\
\text { Programas } \\
\text { não } \\
\text { customi- } \\
\text { záveis }\end{array}$ \\
\hline 23.016 - Fortaleza & 30 & 485 & 16 & 1.391 & 0,9 & 1,2 & 0,63 & 62,5 & 6,2 & 31,3 \\
\hline 26.017-Recife & 45 & 620 & 14 & 1.417 & 1,1 & 1,6 & 0,80 & 53,1 & 5,5 & 41,5 \\
\hline 29.021 - Salvador & 35 & 1.157 & 33 & 1.252 & 2,1 & 2,4 & 1,26 & 6,5 & 9,0 & 84,5 \\
\hline 31.018 - Uberlândia & 23 & 204 & 9 & 1.357 & 0,4 & 1,1 & 0,55 & 10,3 & 61,8 & 27,9 \\
\hline 31.022 - Uberaba & 7 & 278 & 40 & 2.362 & 0,5 & 3,0 & 1,55 & 74,8 & 0,0 & 25,2 \\
\hline 31.030 - Belo Horizonte & 201 & 6.427 & 32 & 1.053 & 11,7 & 7,1 & 3,64 & 79,6 & 8,6 & 11,8 \\
\hline 32.006 - Linhares & 2 & 301 & 151 & 2.292 & 0,5 & 4,9 & 2,50 & 1,3 & 0,0 & 98,7 \\
\hline 32.009 - Vitória & 51 & 448 & 9 & 1.551 & 0,8 & 1,5 & 0,79 & 67,2 & 8,3 & 24,6 \\
\hline 33.003 - Campos & 2 & 282 & 141 & 1.587 & 0,5 & 3,6 & 1,83 & 98,6 & 1,4 & 0,0 \\
\hline 33.015 - Serrana & 15 & 300 & 20 & 1.150 & 0,5 & 3,2 & 1,64 & 16,3 & 41,3 & 42,3 \\
\hline 33.018 - Rio de Janeiro & 238 & 4.755 & 20 & 2.618 & 8,6 & 3,0 & 1,54 & 50,1 & 2,6 & 47,3 \\
\hline 35.004 - S. José do Rio Preto & 18 & 155 & 9 & 1.127 & 0,3 & 0,8 & 0,42 & 68,4 & 0,6 & 31,0 \\
\hline 35.014 - Ribeirão Preto & 25 & 215 & 9 & 1.522 & 0,4 & 0,9 & 0,47 & 65,1 & 3,7 & 31,2 \\
\hline 35.032 - Campinas & 71 & 3.107 & 44 & 1.607 & 5,6 & 6,2 & 3,17 & 69,8 & 17,9 & 12,3 \\
\hline 35.046 - Sorocaba & 20 & 157 & 8 & 1.569 & 0,3 & 0,7 & 0,37 & 32,5 & 7,6 & 59,9 \\
\hline 35.050 - S. José dos Campos & 29 & 284 & 10 & 1.598 & 0,5 & 1,3 & 0,66 & 32,4 & 10,2 & 57,4 \\
\hline
\end{tabular}


Inovação, cooperação e aprendizado no setor de software no Brasil: análise exploratória baseada no conceito de APLs

Tabela 7 - Continuação

\begin{tabular}{|c|c|c|c|c|c|c|c|c|c|c|}
\hline Microrregiões & $\begin{array}{l}\text { Estabele- } \\
\text { cimentos }\end{array}$ & Empregos & $\begin{array}{c}\text { Tama- } \\
\text { nho } \\
\text { Médio }\end{array}$ & $\begin{array}{c}\text { Remune- } \\
\text { ração } \\
\text { Média }\end{array}$ & $\begin{array}{c}\% \text { no } \\
\text { Emprego } \\
\text { setorial }\end{array}$ & $\begin{array}{c}\% \text { do } \\
\text { setor no } \\
\text { emprego } \\
\text { da } \\
\text { Micror- } \\
\text { região }\end{array}$ & $\begin{array}{c}\text { Índice } \\
\text { de } \\
\text { especia- } \\
\text { lização } \\
\text { relativa } \\
\text { (QL) }\end{array}$ & $\begin{array}{c}\% \\
\text { Emprego - } \\
\text { Programas } \\
\text { sob } \\
\text { encomenda }\end{array}$ & $\begin{array}{c}\% \\
\text { Emprego - } \\
\text { Programas } \\
\text { customi- } \\
\text { záveis }\end{array}$ & $\begin{array}{c}\% \\
\text { Emprego - } \\
\text { Programas } \\
\text { não } \\
\text { customi- } \\
\text { záveis }\end{array}$ \\
\hline 35.057 - Osasco & 133 & 3.280 & 25 & 2.455 & 6,0 & 15,4 & 7,94 & 65,5 & 8,7 & 25,7 \\
\hline 35.061 - São Paulo & 652 & 13.080 & 20 & 2.999 & 23,7 & 5,0 & 2,55 & 58,1 & 5,5 & 36,4 \\
\hline 35.062 - Mogi das Cruzes & 41 & 623 & 15 & 4.239 & 1,1 & 4,6 & 2,39 & 38,4 & 0,0 & 61,6 \\
\hline 41.009 - Maringá & 12 & 163 & 14 & 1.289 & 0,3 & 1,0 & 0,54 & 9,2 & 2,5 & 88,3 \\
\hline 41.011 - Londrina & 23 & 194 & 8 & 1.017 & 0,4 & 1,1 & 0,55 & 39,2 & 23,2 & 37,6 \\
\hline $41.037-$ Curitiba & 95 & 831 & 9 & 1.828 & 1,5 & 1,3 & 0,64 & 58,8 & 16,6 & 24,5 \\
\hline 42.008 - Joinville & 37 & 1.086 & 29 & 2.362 & 2,0 & 5,9 & 3,02 & 76,5 & 4,0 & 19,5 \\
\hline 42.012 - Blumenau & 66 & 1.095 & 17 & 1.635 & 2,0 & 5,4 & 2,75 & 16,6 & 7,2 & 76,2 \\
\hline 42.016 - Florianópolis & 79 & 1.073 & 14 & 2.444 & 1,9 & 4,6 & 2,35 & 62,7 & 11,7 & 25,5 \\
\hline 43.016 - Caxias do Sul & 36 & 285 & 8 & 1.278 & 0,5 & 1,3 & 0,66 & 24,6 & 17,2 & 58,2 \\
\hline 43.026 - Porto Alegre & 138 & 1.542 & 11 & 1.746 & 2,8 & 2,0 & 1,01 & 42,3 & 19,7 & 37,9 \\
\hline 50.004 - Campo Grande & 19 & 741 & 39 & 797 & 1,3 & 4,6 & 2,34 & 18,1 & 1,6 & 80,3 \\
\hline 52.010 - Goiânia & 34 & 1.045 & 31 & 1.603 & 1,9 & 2,6 & 1,32 & 30,1 & 2,8 & 67,1 \\
\hline 53.001-Brasília & 104 & 7.079 & 68 & 2.215 & 12,8 & 15,7 & 8,08 & 48,0 & 43,0 & 9,0 \\
\hline Subtotal & 2.281 & 51.292 & 22 & 2.171 & 92,9 & 4,1 & 2,01 & 55,5 & 12,9 & 31,6 \\
\hline Total & 2.841 & 55.101 & 19 & 2.100 & 100,0 & 1,9 & 1,00 & 55,0 & 13,2 & 31,8 \\
\hline
\end{tabular}

Fonte: Elaboração própria a partir de informações extraídas da RAIS - MTE (2006). 
Jorge Britto / Fabio Stallivieri

A partir de uma comparação interterritorial dessas informações, alguns aspectos podem ser ressaltados. Em primeiro lugar, cabe observar que, conforme esperado, a maioria das aglomerações está localizada em regiões mais desenvolvidas do país. De fato, 11 aglomerações estavam localizadas no estado de São Paulo, compreendendo aproximadamente $37,9 \% \quad(23,7 \%$ apenas na microrregião da capital do estado) dos empregos gerados pela indústria. São Paulo era acompanhado pelo Distrito Federal com 12,8\% dos empregos gerados pela indústria de software (devido à presença de empresas que atendem basicamente ao setor público, conforme já mencionado), Belo Horizonte $(11,7 \%)$ e um conjunto de aglomerações localizadas na região sul do país (compreendendo os estados do Paraná, Santa Catarina e Rio Grande do Sul) as quais eram responsáveis por $11,4 \%$ dos empregos criados naquelas atividades.

Em segundo lugar, é possível observar diferenças relevantes no padrão de especialização produtiva em atividades dedicadas ao desenvolvimento de software nas aglomerações selecionadas. Considerando um índice de "especialização relativa" calculado para o total de empregos gerados, observa-se que em 11 microrregiões esse índice era superior a 2, indicando uma forte especialização da economia local em atividades dedicadas à produção de software: Brasília, Osasco, Blumenau, Joinville, Campinas, Linhares, Belo Horizonte, Uberaba, Campo Grande, Florianópolis e Serrana (RJ). Esses padrões de especialização podem também ser articulados à diferenciação entre software sob encomenda, customizáveis e não customizáveis em dois grupos de microrregiões. O primeiro é composto por 11 aglomerações com mais de $70 \%$ do emprego em atividades de software concentrado no segmento de softwares sob encomenda ou customizáveis: Campos dos Goytacazes, Brasília, Belo Horizonte, Campinas, Joinville, Curitiba, Vitória, Uberaba, Florianópolis, Osasco, Uberlândia. O outro grupo é composto por sete aglomerações com mais de $60 \%$ do emprego concentrado no segmento de software não customizáveis: Mogi das Cruzes, Goiânia, Blumenau, Campo Grande, Salvador, Maringá e Linhares.

Em terceiro lugar, é possível também observar diferenças significativas no tamanho médio das empresas nas aglomerações selecionadas. Apesar de a média geral (19 empregados por estabelecimento) denotar um predomínio de MPEs, é possível contrastar diferenças expressivas entre dois grupos de aglomerações. $\mathrm{O}$ primeiro grupo envolve aglomerações com mais de 30 empregados por estabelecimento, localizadas nas microrregiões de Campos dos Goytacazes, Linhares, Brasília, Campinas, Campo Grande, Uberaba e Belo Horizonte. O segundo grupo compreende aglomerações com menos de oito empregados por estabelecimento, localizadas nas microrregiões de Ribeirão Preto, Londrina, 
Vitória, Curitiba, Caxias do Sul, Sorocaba e Uberlândia. Por fim, as evidências coletadas demonstram que os salários pagos nas aglomerações selecionadas também apresentam expressivas variações. É possível observar que apenas sete aglomerações pagavam mais de $\mathrm{R} \$ 2.300$ ao mês por empregado no ano de 2006: Mogi das Cruzes, São Paulo, Rio de Janeiro, Osasco, Florianópolis, Joinville e Uberaba. Por outro lado, oito aglomerações pagavam salários mensais inferiores a R\$ 1.300 em 2006. Esses salários eram particularmente menores em aglomerações localizadas em algumas microrregiões como Maringá, Caxias do Sul, Salvador, Serrana (RJ), São José do Rio Preto, Belo Horizonte, Londrina e Campo Grande.

A partir do mapa geral de aglomerações produtivas identificadas na seção anterior, é possível avançar na discussão sobre a natureza localizada do processo de inovação e aprendizado na produção de software. Em função da disponibilidade de informações coletadas em pesquisas empíricas realizadas no âmbito do estudo "MPEs em Arranjos Produtivos Locais no Brasil", realizado pela UFSC e o SEBRAE-NA, e em pesquisas da RedeSist, é possível considerar quatro das aglomerações identificadas a partir do procedimento anterior, em relação às quais existe algum grau de articulação dos agentes locais condizente com a definição estilizada de "arranjos produtivos locais", as quais estão localizadas na microrregiões de Recife-PE, Serrana-RJ (a qual tem como núcleo central o município de Petrópolis), Curitiba-PR e Brasília-DF. Essas microrregiões eram responsáveis pela geração de 8.830 empregos no setor de software em 2006, congregando 259 estabelecimentos. Em termos dos padrões de especialização relativa, observam-se índices mais elevados em Brasília-DF $(8,08)$ e na região Serrana-RJ $(1,64)$, comparativamente às microrregiões de Recife-PE $(0,80)$ e de Curitiba $(0,64)$. Quanto à distribuição do emprego pelo desenvolvimento dos diversos tipos de software, observa-se em Recife e Curitiba uma maior importância do emprego no desenvolvimento de softwares sob encomenda, enquanto na região Serrana (RJ) o mesmo se reparte entre o desenvolvimento e o licenciamento de softwares customizáveis e não customizáveis. Finalmente, em Brasília, o emprego se reparte entre o desenvolvimento de softwares sob encomenda e customizáveis.

A Tabela 8 apresenta a distribuição dos estabelecimentos e do emprego por diferentes faixas de tamanho de estabelecimento, ${ }^{11}$ para as diversas classes CNAE associadas ao desenvolvimento de software nas microrregiões selecionadas. Percebem-se diferenças importantes entre as diversas aglomerações.

(11) Considerou-se, nesse caso, uma diferenciação entre quatro faixas de tamanho de estabelecimento: 1) Microempresa (com até 19 empregados); 2) Pequena empresa (entre 20-99 empregados); 3) Média empresa (entre 100-499 empregados); 4) Grande empresa (mais de 500 empregados). 
No caso de Recife, há uma clara predominância do emprego em micro e pequenas empresas. Na região Serrana, o emprego concentra-se na faixa de média empresa, enquanto em Curitiba verifica-se uma distribuição mais igualitária do emprego entre as diversas faixas de tamanho. Finalmente, no caso de Brasília observa-se uma nítida concentração do emprego na faixa de grande empresa. Essas diferenças refletem particularidades da maneira como se estruturaram cada uma dessas aglomerações.

No caso de Recife, verifica-se uma confluência de MPEs de base tecnológica dinâmica em torno da região do "Porto Digital". Esse arranjo estruturou-se a partir da governança promovida pelo Núcleo de Gestão do Porto Digital (NGPD), uma associação civil sem fins lucrativos, da constituição de incubadoras de empresas - como o CAIS do Porto, que congrega empresas na área de software e Centro Apolo de Integração de Suporte, que atua na área de TICs desde 2003 -, do suporte da infraestrutura científica provida pelo Centro de Estudos e Sistemas Avançados do Recife (CESAR), associado ao Centro de Informática da UFPE e do apoio da Secretaria de Ciência, Tecnologia e Meio Ambiente (SECTMA) do Governo do Estado de Pernambuco. Esse núcleo articula-se também ao SoftexRecife - Centro de Tecnologia de Software para Exportação do Recife - cuja origem está vinculada ao Programa Softex 2000 e congrega aproximadamente 50 empresas que atuam em parceria com o Porto Digital em projetos de desenvolvimento de software para exportação.

A aglomeração situada na região Serrana do Estado do Rio de Janeiro surgiu a partir da ideia de constituir um polo de alta tecnologia na cidade em meados dos anos 1980, que estimulou a criação da Fundação Parque de Alta Tecnologia de Petrópolis (Funpat) em 1986, a partir da qual estruturou-se o projeto Petrópolis-Tecnópolis. Estudos realizados (Cassiolato et al., 2003) indicavam a presença de algo em torno de 30 micro e pequenas atuantes no local, destacando-se ainda a presença "indireta" da Microsoft e da IBM que implantaram centros de treinamento na região, assim como a presença do Laboratório Nacional de Computação Científica (LNCC). As evidências sugerem que o arranjo é constituído principalmente por empresas jovens, micro e pequenas, a maioria das quais atraída principalmente pelas políticas de isenção fiscal, baixo custo de instalação e principalmente pelas perspectivas de apoio institucional, público e privado, inclusive em função da proximidade de instituições de ensino e pesquisa com potencial para formar recursos humanos qualificados para o setor.

No caso de Curitiba, o aglomerado foi se estruturando de forma relativamente natural, como reflexo das demandas criadas a partir de empresas instaladas na Cidade Industrial de Curitiba (CIC) e da disponibilidade de uma 
ampla infraestrutura científico-tecnológica. Nesse caso, destacam-se as ações de instituições de ensino como o CEFET, a UFPR e a PUC-PR, assim como o papel da Incubadora Tecnológica do Paraná (INTEC), instalada nas dependências do Instituto de Tecnologia do Pará (TECPAR), bem como a constituição do Centro Internacional de Tecnologia de Software (CITS), o primeiro núcleo efetivo estruturado a partir do Programa SOFTEX (Scatolin; Sampaio, 2004).

Por fim, o caso de Brasília caracteriza-se pela presença de algumas grandes empresas que prestam serviços aos diversos órgãos de governo e por um conjunto de pequenas e médias empresas em posição secundária. Esse arranjo estruturou-se a partir da necessidade de armazenamento e transmissão segura e codificada de dados por parte de diversos órgãos do governo. Essa demanda foi fortalecida pela atração para o DF das grandes empresas e grandes bancos estatais, com seus centros de TI, além de agências internacionais, embaixadas e ONGs. Desse modo, o governo federal criou um mercado de software que estimulou a criação de empresas locais. O processo teve continuidade com a saída de técnicos especializados de órgãos do governo federal e de suas autarquias/estatais, que disponibilizaram mão de obra qualificada e com algum capital para o setor privado, o que originou diversas empresas de pequeno porte, cujo crescimento esteve atrelado aos investimentos do governo federal em TI que muitas vezes demandam soluções customizadas, em que a interação com o cliente é fundamental. Nessa dinâmica, as políticas com maior impacto no arranjo são as executadas por meio da Tecsoft, agente local Softex, as quais envolvem o apoio à exportação (particularmente por meio de um consórcio de exportação denominado Brains - Brazilian Intelligence Software), da capacitação em gestão, do financiamento, e do aumento da qualidade e produtividade no desenvolvimento de software. Na estrutura do arranjo, destacam-se, além das empresas de software e do governo federal, o governo local, a Sociedade para Promoção do Software Brasileiro (Softex), o Centro de Tecnologia de Software de Brasília (Tecsoft), representação regional da Softex e diversas instituições de ensino. Mais recentemente, a competição pelas demandas, via editais, do setor público gerou uma intensificação da divisão de trabalho no interior do arranjo, especializando as grandes firmas no atendimento da demanda de determinados órgãos e restringindo o campo para uma atuação mais ampla de MPEs (Fernandes; Balestro; Motta, 2004). 
Tabela 8

Estabelecimentos e empregos por faixa de tamanho de estabelecimento em aglomerações selecionadas - 2006

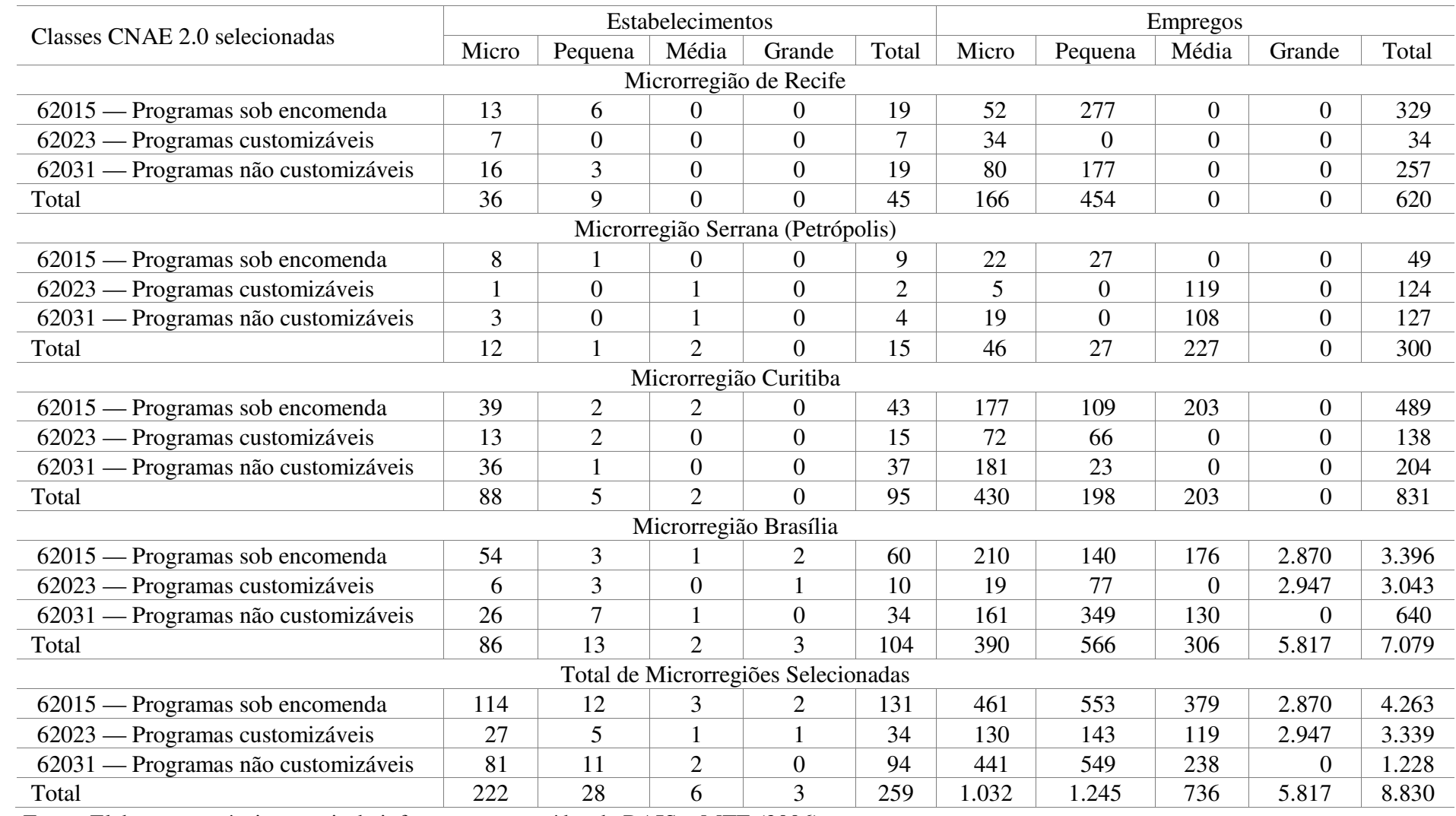

Fonte: Elaboração própria a partir de informações extraídas da RAIS - MTE (2006). 


\section{Arranjos produtivos no setor de software: uma análise multivariada exploratória}

Procura-se nesta seção desenvolver uma análise exploratória sobre os fatores que afetam os padrões de aprendizado, cooperação e inovação em um conjunto particular de arranjos produtivos locais (APLs) dedicados à produção de software. A análise está baseada em quatro estudos de caso localizados nas regiões de Petrópolis (RJ), Curitiba (PR), Recife (PE) e Brasília (DF), desenvolvidos no âmbito das atividades da Redesist. A base empírica da investigação é composta por 131 firmas inseridas nesses quatro APLs. Destaca-se, no tocante à base de empresas investigadas, uma clara predominância de MPMEs, conforme aponta a Tabela 9.

Tabela 9

Características de firmas inseridas em APLs investigados

\begin{tabular}{l|c|c|c|c|c|c}
\hline \multicolumn{2}{c|}{$\begin{array}{c}\text { APL / Porte dos } \\
\text { Estabelecimentos }\end{array}$} & Microempr. & Pequena Empr. & Média Empr. & $\begin{array}{c}\text { Grande } \\
\text { Empr. }\end{array}$ & Total \\
\hline \multirow{2}{*}{ Brasília } & $\mathrm{n}^{\mathbf{o}}$ & 33 & 15 & 3 & 1 & 52 \\
\cline { 2 - 7 } & $\%$ & 63,46 & 28,85 & 5,77 & 1,92 & 100 \\
\hline \multirow{2}{*}{ Curitiba } & $\mathrm{n}^{-}$ & 13 & 7 & 4 & 1 & 25 \\
\cline { 2 - 7 } & $\%$ & 52,00 & 28,00 & 16,00 & 4,00 & 100 \\
\hline \multirow{2}{*}{ Petrópolis } & $\mathrm{n}^{-}$ & 16 & 2 & 0 & 0 & 18 \\
\cline { 2 - 8 } & $\%$ & 88,89 & 11,11 & 0 & 0 & 100 \\
\hline \multirow{2}{*}{ Recife } & $\mathrm{n}^{-}$ & 32 & 3 & 1 & 0 & 36 \\
\cline { 2 - 7 } & $\%$ & 88,89 & 8,33 & 2,78 & 0 & 100 \\
\hline \multirow{2}{*}{ Total } & $\mathrm{n}^{-}$ & 94 & 27 & 8 & 2 & 131 \\
\cline { 2 - 7 } & $\%$ & 71,76 & 20,61 & 6,11 & 1,53 & 100 \\
\hline
\end{tabular}

Fonte: Base de dados sobre APLs - RedeSist.

A análise está baseada em um conjunto de indicadores construídos com base em informações coletadas na avaliação empírica daquelas aglomerações, os quais procuram ressaltar aspectos relacionados aos padrões de aprendizado, cooperação e inovação em cada contexto institucional particular. Essa análise constitui uma tentativa de avançar-se no tratamento de informações coletadas por meio de questionários aplicados junto a empresas inseridas em APLs, visando obter-se algum tipo de mensuração das formas de interação, cooperação e formas de aprendizado características desses arranjos. Procura-se, a partir desse tratamento, avaliar as possibilidades de um determinado arranjo evoluir ao longo de uma trajetória "virtuosa" de fortalecimento da capacitação inovativa dos agentes inseridos em APLs. Para a construção de indicadores, procurou-se utilizar um conjunto de questões extraídas do questionário básico da investigação. Uma vez selecionadas as questões, procurou-se transformar atributos qualitativos, como a importância atribuída pela empresa a determinado evento, em quantitativos, encontrando-se um valor entre 0 a 1 que expressasse a opinião da empresa sobre 
cada evento. Esses indicadores referem-se, portanto, à média ponderada da importância atribuída pelo conjunto das empresas a determinada questão, transformando a opinião de cada empresa num indicador que varia entre 0 e 1 .

Quatro grupos de indicadores, extraídos e normalizados a partir de informações extraídas da base de dados sobre APLs produtores de software, foram considerados. O primeiro grupo procura captar as origens internas e externas das informações utilizadas pelas empresas em seus processos de aprendizado. $\mathrm{O}$ segundo grupo procura avaliar a intensidade dos esforços tecnológicos realizados pelas firmas integradas àqueles arranjos, vistos como um requisito para incrementar e incorporar os possíveis ganhos de aprendizado gerados pela consolidação dos mesmos. O terceiro grupo de indicadores refere-se à natureza das práticas cooperativas adotadas pelas empresas inseridas naqueles arranjos. Por fim, o quarto grupo de indicadores procura contemplar aspectos relacionados ao desempenho inovativo das firmas inseridas nos arranjos investigados. De maneira a contemplar essas dimensões, um conjunto de 19 (dezenove) indicadores foi selecionado para a realização de uma análise "exploratória". O Quadro 1 apresenta os indicadores selecionados para as diversas dimensões da análise.

Quadro 1

Indicadores normalizados construídos com base em informações de estudos empíricos

\begin{tabular}{|c|}
\hline 1 - Atividades de Aprendizado \\
\hline Aprendizagem Interna (APRINT) \\
\hline Aprendizagem Agentes Produtivos (APRAGPR) \\
\hline Aprendizagem Agentes de C\&T (APRC\&T) \\
\hline Aprendizagem Demais Agentes (APRDMAG) \\
\hline 2 - Esforços Inovativos \\
\hline Esforço de Treinamento de RH (ESFTRE) \\
\hline Esforço de Absorção de RH (ESFABS) \\
\hline Constância nas Atividades Inovativas (COATIN) \\
\hline Constância no Desenvolvimento de P\&D (CONP\&D) \\
\hline Constância na Compra de Tecnologias (CONOUTC) \\
\hline Constância Novas Formas de Comerc. (COFORCOM) \\
\hline 3 - Práticas Cooperativas \\
\hline Cooperação Vertical (COPVER) \\
\hline Cooperação Horizontal (COPHOR) \\
\hline Cooperação Serviços Especializados (COPSRESP) \\
\hline Cooperação Demais Agentes (COPDMAG) \\
\hline 4 - Performance Inovativa \\
\hline Inovação Radicais em Produtos (INPD1) \\
\hline Inovações Radicais em Processos (INPC1) \\
\hline Inovações Incrementais em Produtos (INPD2) \\
\hline Inovações Incrementais em Processos (INPC2) \\
\hline Inovações Organizacionais (INORG) \\
\hline
\end{tabular}

Nota: indicadores são normalizados de zero a 1. 
A Tabela 10 apresenta valores para cada um dos quatro grupos de indicadores calculados para os APLs investigados, construídos como uma média simples dos indicadores individuais normalizados que compõem cada grupo. Essas informações possibilitam contrastar algumas características dos processos de aprendizado e inovação em cada um dos arranjos investigados. De início, cabe ressaltar que qualquer conclusão extraída dos dados deve ser qualificada, em função do elevado valor do desvio padrão comparado às médias calculadas, o que sugere uma expressiva heterogeneidade entre as firmas investigadas no tocante às suas estratégias e competências. Apesar dessa heterogeneidade geral, as informações também sinalizam na direção de algumas tendências importantes, como o baixo nível de cooperação, talvez com a exceção de Petrópolis, onde o indicador associado àquelas práticas assume um valor superior ao observado nos demais arranjos. Os processos de aprendizado parecem ser mais intensos em Petrópolis e Curitiba, enquanto os indicadores relativos aos esforços inovativos apresentam-se mais elevados em Curitiba. A assimetria geral observada entre os indicadores de aprendizado e os de cooperação parece indicar que a cooperação não é ainda percebida como um elemento efetivamente importante no delineamento das estratégias tecnológicas das empresas do setor.

Tabela 10

Média e desvio padrão de indicadores construídos para APLs

\begin{tabular}{l|c|c|c|c|c|c|c|c|c|c}
\hline \multirow{2}{*}{$\begin{array}{l}\text { Tipo de } \\
\text { Indicador }\end{array}$} & \multicolumn{2}{|c|}{ Amostra } & \multicolumn{2}{c|}{ Petrópolis } & \multicolumn{2}{c|}{ Curitiba } & \multicolumn{2}{c|}{ Recife } & \multicolumn{2}{c}{ Brasília } \\
\cline { 2 - 11 } & Média & $\begin{array}{c}\text { Desv. } \\
\text { Pad. }\end{array}$ & Média & $\begin{array}{c}\text { Desv. } \\
\text { Pad. }\end{array}$ & Média & $\begin{array}{c}\text { Desv. } \\
\text { Pad. }\end{array}$ & Média & $\begin{array}{c}\text { Desv. } \\
\text { Pad. }\end{array}$ & Média & $\begin{array}{c}\text { Desv. } \\
\text { Pad. }\end{array}$ \\
\hline $\begin{array}{l}\text { Aprendizado } \\
\text {-Atividades de }\end{array}$ & 0,434 & 0,255 & 0,547 & 0,217 & 0,518 & 0,223 & 0,370 & 0,249 & 0,399 & 0,256 \\
\hline $\begin{array}{l}\text { I- Esforços } \\
\text { Inovativos }\end{array}$ & 0,402 & 0,313 & 0,383 & 0,306 & 0,487 & 0,289 & 0,350 & 0,323 & 0,404 & 0,308 \\
\hline $\begin{array}{l}\text { 3- Práticas } \\
\text { Cooperativas }\end{array}$ & 0,164 & 0,241 & 0,360 & 0,278 & 0,147 & 0,223 & 0,063 & 0,191 & 0,174 & 0,226 \\
\hline $\begin{array}{l}\text { 4-Performance } \\
\text { Inovativa }\end{array}$ & 0,428 & 0,408 & 0,447 & 0,388 & 0,539 & 0,413 & 0,359 & 0,394 & 0,416 & 0,404 \\
\hline Média Geral & 0,365 & 0,311 & 0,430 & 0,303 & 0,436 & 0,294 & 0,296 & 0,298 & 0,357 & 0,305 \\
\hline
\end{tabular}

Obs.: indicadores normalizados entre zero e 1.

Fonte: Informações extraídas da Base de dados sobre APLs - RedeSist.

Dando continuidade à análise, procura-se manipular os indicadores construídos através da utilização de ferramentas estatísticas de análise multivariada, de forma a identificar diferentes clusters de firmas com características similares em termos dos seus processos de aprendizado, cooperação 
e inovação. ${ }^{12}$ A partir da análise feita anteriormente, e utilizando-se o método de agrupamento não hierárquico, testou-se a amostra para 3, 4, 5, 6 e 7 agrupamentos respectivamente. Os melhores resultados foram obtidos com 5 agrupamentos, no qual as variáveis foram mais significantes, bem como apresentaram uma distribuição $F$ mais elevada para a maioria das variáveis. ${ }^{13}$ Optou-se, portanto, por agrupar as empresas em cinco (5) clusters distintos. Os resultados em relação à média das variáveis para cada cluster identificado são apresentados na Tabela 11 .

Com base nos dados apresentados, é possível verificar que todos os indicadores utilizados são estatisticamente significantes a um nível de 5\%, por apresentarem o valor $p$ reduzido. Um outro ponto a ser observado é que, através da distância $F$, podemos afirmar que os indicadores que mais estão contribuindo para a formação dos clusters são, respectivamente: inovações incrementais em processos (INPRC2), inovações radicais em produtos (INPRO1), constância no desenvolvimento de atividades inovativas (COATIN), constância no desenvolvimento de $\mathrm{P} \& \mathrm{D}(\mathrm{CONP} \& \mathrm{D})$, constância no desenvolvimento de novas formas de organização (COFORCOM) e esforço de absorção de RH qualificados (ESFABS). Percebe-se, também, que todas as demais variáveis, em menor ou maior grau, estão influenciando na formação dos clusters. Portanto, com base nos testes estatísticos, pode-se concluir que existem diferenças significativas entre os clusters identificados.

Em relação ao conjunto das 131 empresas analisadas, nota-se, com base nos indicadores de aprendizagem, que as fontes internas de informação $($ APRINT $=0,60)$ assumem maior relevância. Em relação às fontes externas, ocorre um intensivo uso de informações relacionadas a agentes produtivos (APRAGPR $=0,43)$ e aos demais agentes (APRDMAG $=0,46)$, paralelamente a uma menor importância atribuída às fontes de informação relacionadas a agentes de C\&T. A cooperação ocorre principalmente ao longo da cadeia produtiva, sendo que as relações cooperativas mais importantes referem-se aos fornecedores e clientes, materializadas no indicador de cooperação vertical $(0,25)$.

(12) Procurando-se garantir a "robustez" dos clusters identificados, optou-se pela utilização de dois métodos de clusterização. Num primeiro momento utilizou-se um método de agrupamento hierárquico (método Joining), para se ter uma noção aproximada do número de clusters a serem identificados. Num segundo momento, aplicou-se um método de aglomeração não hierárquico, baseado no cálculo de $K$-médias, estipulando o número de clusters a serem identificados na análise. No desenvolvimento desse método, utilizou-se a opção de ligações completas e a medida de distância geométrica/espacial adotada foi o "quadrado da distância Euclidiana". Os resultados apresentados no dendograma sugeriram a existência de 3 a 7 agrupamentos distintos de empresas, em função da distância/altura de corte selecionada.

(13) Segundo Johnson e Wichern (1998), uma forma de verificar, utilizando o método de K-médias, se uma análise com números diferentes de cluster é mais eficaz consiste em comparar as distâncias $\mathrm{F}$ das variáveis nos diferentes números de agrupamentos especificados. $\mathrm{O}$ melhor número de agrupamentos é aquele cujos $\mathrm{F}$ relativos às variáveis apresentam os maiores valores. 
Tabela 11

Análise de cluster segundo as variáveis apresentadas para as empresas de software $(\mathrm{N}=131)$ :

\begin{tabular}{|c|c|c|c|c|c|c|c|c|c|}
\hline Indicadores/ Clusters & $\begin{array}{c}\text { Cluster } \\
1(22 \\
\text { Firmas })\end{array}$ & $\begin{array}{c}\text { Cluster } \\
2(25 \\
\text { Firmas })\end{array}$ & $\begin{array}{c}\text { Cluster } \\
3(34 \\
\text { Firmas) }\end{array}$ & $\begin{array}{c}\text { Cluster } \\
4(20 \\
\text { Firmas })\end{array}$ & $\begin{array}{c}\text { Cluster } \\
5(30 \\
\text { Firmas })\end{array}$ & $\begin{array}{c}\text { Média } \\
\text { (131 } \\
\text { Firmas) }\end{array}$ & $\begin{array}{l}\text { Stand } \\
\text { Devo }\end{array}$ & $F$ & $\begin{array}{c}\text { Signific. } \\
P\end{array}$ \\
\hline Aprendizagem Interna (APRINT) & 0,7148 & 0,6155 & 0,5546 & 0,3738 & 0,7480 & 0,6098 & 0,307 & 6,293 & 0,0001 \\
\hline Aprendizagem Agentes Produtivos (APRAGPR) & 0,4528 & 0,4243 & 0,4100 & 0,2821 & 0,5448 & 0,4313 & 0,221 & 4,939 & 0,0010 \\
\hline Aprendizagem Agentes de C\&T (APRC\&T) & 0,3161 & 0,1988 & 0,1415 & 0,1286 & 0,3738 & 0,2330 & 0,256 & 5,566 & 0,0004 \\
\hline Aprendizagem Demais Agentes (APRDMAG) & 0,5834 & 0,4890 & 0,3824 & 0,2965 & 0,5557 & 0,4631 & 0,238 & 7,161 & 0,0000 \\
\hline Cooperação Vertical (COPVER) & 0,3775 & 0,2392 & 0,1856 & 0,0745 & 0,3873 & 0,2573 & 0,316 & 4,667 & 0,0015 \\
\hline Cooperação Horizontal (COPHOR) & 0,1959 & 0,1458 & 0,0879 & 0,0998 & 0,3095 & 0,1697 & 0,272 & 3,411 & 0,0110 \\
\hline Cooperação Serviços Especializados (COPSRESP) & 0,1987 & 0,0714 & 0,0545 & 0,0331 & 0,2411 & 0,1214 & 0,199 & 6,924 & 0,0000 \\
\hline Cooperação Demais Agentes (COPDMAG) & 0,1809 & 0,1026 & 0,0585 & 0,0331 & 0,1575 & 0,1063 & 0,175 & 3,389 & 0,0114 \\
\hline Esforço de Treinamento de RH (ESFTRE) & 0,3679 & 0,3798 & 0,3068 & 0,2824 & 0,5025 & 0,3721 & 0,210 & 5,241 & 0,0006 \\
\hline Esforço de Absorção de RH (ESFABS) & 0,2861 & 0,2649 & 0,1707 & & 0,4672 & 0,2606 & 0,246 & 13,022 & 0,0000 \\
\hline Constância nas Atividades Inovativas (COATIN) & 0,5114 & 0,5050 & 0,1654 & 0,2531 & 0,6229 & 0,4065 & 0,241 & 42,186 & 0,0000 \\
\hline Constância no Desenvolvimento de P\&D (CONP\&D) & 0,5909 & 0,5500 & 0,1176 & 0,2375 & 0,6750 & 0,4256 & 0,350 & 23,297 & 0,0000 \\
\hline Constância na Compra de Tecnologias (CONOUTC) & 0,5455 & & 0,2206 & & 0,7167 & 0,5305 & 0,406 & 13,306 & 0,0000 \\
\hline Constância Novas Formas de Comerc. (COFORCOM) & 0,6818 & 0,6000 & 0,1471 & 0,0500 & 0,6167 & 0,4160 & 0,426 & 18,581 & 0,0000 \\
\hline Inovações Radicais em Produtos (INPD1) & 0,3864 & 0,5400 & 0,0735 & 0,1750 & 0,5167 & 0,3321 & 0,375 & 11,624 & 0,0000 \\
\hline Inovações Radicais em Processos (INPC1) & 0,0000 & 0,4800 & 0,0294 & 0,4500 & 1,0000 & 0,3969 & 0,491 & 49,730 & 0,0000 \\
\hline Inovações Incrementais em Produtos (INPD2) & 0,6212 & 0,4133 & 0,2255 & 0,3500 & 0,5000 & 0,4097 & 0,322 & 7,025 & 0,0000 \\
\hline Inovações Incrementais em Processos (INPC2) & 0,9545 & 0,0000 & 0,0000 & 1,0000 & 1,0000 & 0,5420 & 0,500 & 1041,630 & 0,0000 \\
\hline Inovações Organizacionais (INORG) & 0,5182 & 0,5520 & 0,2647 & 0,3400 & 0,6400 & 0,4595 & 0,351 & 6,819 & 0,0001 \\
\hline
\end{tabular}

Fonte: Informações extraídas da Base de dados sobre APLs - RedeSist. 
As demais formas de cooperação assumem importâncias similares e reduzidas. Nota-se que, para o conjunto das empresas, o esforço de treinamento da mão de obra (ESFTRE) é mais relevante $(0,37)$, comparativamente às estratégias voltadas à absorção (ESFABS) de RH qualificados $(0,26)$. O indicador que exprime a constância das atividades inovativas (COATINV) possui um valor razoavelmente expressivo para o conjunto das empresas $(0,40)$. Porém, nota-se que a principal atividade desenvolvida refere-se à compra de outras tecnologias (CONOTC), com um indicador de 0,53 , seguida pelo desenvolvimento de P\&D (CONP\&D) - 0,42, e pelo desenvolvimento de novas formas de comercialização (COFORCOM), com um indicador de 0,41. Em relação ao desempenho inovativo, as firmas predominantemente inovam de forma incremental, uma vez que os indicadores referentes à inovação incremental em processos (INPC2), inovações organizacionais (INORG) e inovações incrementais em produtos (INPD2) possuem os mais elevados valores $(0,54,0,45$ e 0,40 , respectivamente). Percebese, porém, que essas mesmas empresas possuem considerável capacidade de inovarem de forma radical, principalmente em relação aos processos produtivos (INPC1), com um indicador de 0,39 e, em menor escala, em relação a produtos $(\mathrm{INPD} 1=0,33)$.

Figura 1

Valores de indicadores para clusters identificados

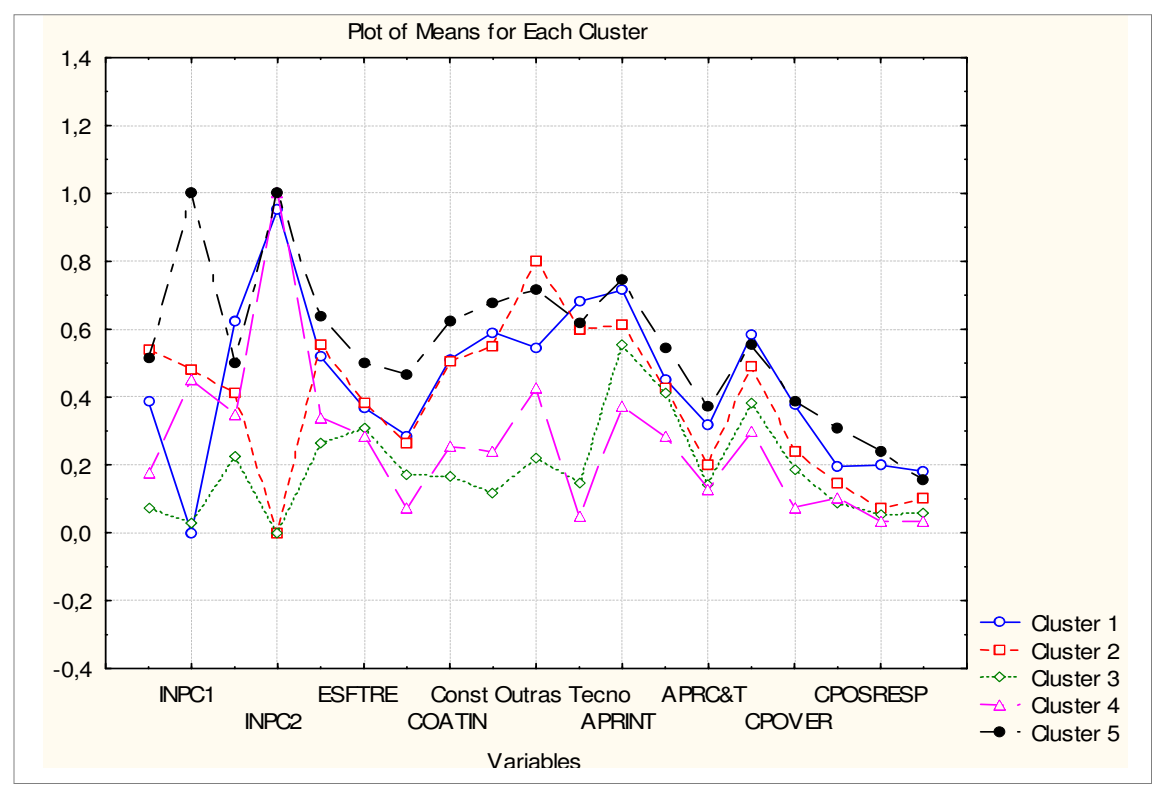

A Figura 1 ilustra o procedimento de agrupamento adotado, apresentando as médias dos indicadores calculados para cada um dos clusters identificados. O Quadro 2, por sua vez, sumariza os resultados obtidos a partir da análise dos valores dos indicadores em cada um dos clusters identificados, ressaltando algumas importantes diferenças entre eles. 
Inovação, cooperação e aprendizado no setor de software no Brasil: análise exploratória baseada no conceito de APLs

Quadro 2

Características dos clusters identificados

\begin{tabular}{|c|c|c|c|c|c|}
\hline Características & $\begin{array}{c}\text { Cluster } 1 \\
\text { (22 Empresas) }\end{array}$ & $\begin{array}{c}\text { Cluster } 2 \\
\text { (25 Empresas) }\end{array}$ & $\begin{array}{c}\text { Cluster } 3 \\
\text { (34 Empresas) }\end{array}$ & $\begin{array}{c}\text { Cluster } 4 \\
\text { (20 Empresas) }\end{array}$ & $\begin{array}{c}\text { Cluster } 5 \\
\text { (30 Empresas) }\end{array}$ \\
\hline $\begin{array}{l}\text { Intensidade no uso de fontes internas } \\
\text { para aprendizagem }\end{array}$ & Alta & Média/alta & Média/alta & Baixa & Alta \\
\hline $\begin{array}{l}\text { Intensidade no uso de fontes externas } \\
\text { para aprendizagem }\end{array}$ & $\begin{array}{c}\text { Média/alta e } \\
\text { principalmente com } \\
\text { demais agentes }\end{array}$ & $\begin{array}{c}\text { Média e } \\
\text { principalmente com } \\
\text { demais agentes }\end{array}$ & $\begin{array}{c}\text { Média e } \\
\text { principalmente com } \\
\text { agentes produtivos }\end{array}$ & Baixa & $\begin{array}{c}\text { Média/alta e } \\
\text { principalmente com } \\
\text { agentes produtivos e } \\
\text { demais agentes }\end{array}$ \\
\hline Intensidade das ações cooperativas & $\begin{array}{l}\text { Média e concentrada } \\
\text { em ações verticais }\end{array}$ & $\begin{array}{l}\text { Média/baixa e } \\
\text { concentrada em } \\
\text { ações verticais }\end{array}$ & $\begin{array}{l}\text { Baixa intensidade e } \\
\text { concentrada em } \\
\text { ações verticais }\end{array}$ & $\begin{array}{c}\text { Baixa/ } \\
\text { inexistência de } \\
\text { cooperação }\end{array}$ & $\begin{array}{c}\text { Média/alta e } \\
\text { concentrada em } \\
\text { ações verticais e } \\
\text { horizontais }\end{array}$ \\
\hline $\begin{array}{l}\text { Esforço de treinamento e absorção de } \\
\text { RH }\end{array}$ & Médio & Médio & $\begin{array}{l}\text { Médio/baixo e } \\
\text { concentrado no } \\
\text { treinamento RH }\end{array}$ & $\begin{array}{l}\text { Médio/baixo e } \\
\text { concentrado no } \\
\text { treinamento RH }\end{array}$ & Alto \\
\hline $\begin{array}{l}\text { Desenvolvimento de atividades } \\
\text { inovativas }\end{array}$ & $\begin{array}{c}\text { Médio/alto e } \\
\text { referente } \\
\text { principalmente a } \\
\text { P\&D e novas formas } \\
\text { de comercialização }\end{array}$ & $\begin{array}{l}\text { Médio/alto e } \\
\text { referente } \\
\text { principalmente à } \\
\text { compra de outras } \\
\text { tecnologias }\end{array}$ & $\begin{array}{l}\text { Baixo e diluído entre } \\
\text { as diversas atividades }\end{array}$ & $\begin{array}{l}\text { Médio/baixo e } \\
\text { referente } \\
\text { principalmente a } \\
\text { compra de outras } \\
\text { tecnologias }\end{array}$ & $\begin{array}{l}\text { Alto e diluído entre } \\
\text { as diversas atividades }\end{array}$ \\
\hline Desempenho inovativo & $\begin{array}{c}\text { Médio e relacionado } \\
\text { a imitação de } \\
\text { produtos e } \\
\text { principalmente } \\
\text { processos }\end{array}$ & $\begin{array}{c}\text { Médio e referente a } \\
\text { produtos e processos } \\
\text { novos e a imitação de } \\
\text { produtos }\end{array}$ & $\begin{array}{l}\text { Baixo com destaque } \\
\text { apenas para imitação } \\
\text { de produtos }\end{array}$ & $\begin{array}{c}\text { Médio com destaque } \\
\text { para a imitação de } \\
\text { processos }\end{array}$ & $\begin{array}{l}\text { Alto e com destaque } \\
\text { para a introdução de } \\
\text { novos processos e } \\
\text { imitação de } \\
\text { processos }\end{array}$ \\
\hline
\end{tabular}


O Cluster 5 parece ser o mais dinâmico quando se consideram os indicadores em conjunto, seguido, a alguma distância, pelo Cluster 1, principalmente em termos de esforços e performance inovativa. O Cluster 5 é também o único no qual as práticas cooperativas parecem ter alguma importância para o processo de construção de competências. Considerando os indicadores em conjunto, os Clusters 2 e 3 localizam-se numa posição intermediária, com o Cluster 2 estando mais bem posicionado em352 termos de processos de aprendizado e práticas cooperativas, enquanto o Cluster 3 parece apresentar uma performance inovativa superior. Finalmente, o Cluster 4 parece estar localizado numa posição inferior comparativamente aos demais, apesar de apresentar uma razoável performance inovativa, assentada principalmente em processos imitativos. Considerando essas diferenças, há indícios de que a capacidade de cada arranjo evoluir ao longo de uma trajetória "virtuosa" de incremento de competências está relacionada não apenas à sua configuração empresarial propriamente dita e à "estrutura de governança" prevalecente em cada contexto, mas também ao "mix" local de competências, que desempenha um papel fundamental para o incremento dos processos de aprendizado e inovação.

Dadas as características estilizadas de cada um dos clusters identificados por meio da análise estatística multivariada, é importante como as empresas dos diferentes arranjos se distribuem entre aqueles clusters, conforme ilustrado pela Tabela 12. Para o conjunto dos arranjos, é possível observar uma distribuição relativamente homogênea das firmas entre os vários clusters. Essa distribuição sugere que existe uma expressiva diversidade entre os níveis de capacitação e o desempenho inovativo das empresas integradas aos arranjos investigados. Analisando-se mais detalhadamente a distribuição dos clusters no âmbito de cada um dos arranjos, as seguintes tendências podem ser captadas: (i) no caso de Brasília, verifica-se uma concentração mais nítida das empresas nos clusters 2 e 3, caracterizados pela posição intermediária em termos da intensidade dos processos de cooperação e aprendizado; (ii) o arranjo de Curitiba destaca-se pela maior concentração relativa de empresas nos clusters 5 (principalmente) e 1, justamente aqueles que a análise apontou como mais dinâmicos em termos da intensidade dos processos de cooperação e aprendizado e do desempenho inovativo; (iii) o arranjo de Petrópolis apresenta uma situação relativamente similar à de Curitiba, porém com uma maior importância relativa do cluster 1, caracterizado pela maior relevância da cooperação vertical e pelo desempenho inovativo intermediário, com predominância de processos imitativos; (iv) no arranjo de Recife, cabe destacar a maior importância relativa do cluster 3. Deve-se ressaltar, no entanto, que essa análise apresenta as limitações inerentes aos procedimentos analíticos adotados e em função das variáveis específicas para orientar a identificação dos diversos clusters. Para avançar na compreensão da dinâmica de operação daqueles arranjos, torna-se necessário correlacionar essas evidências a informações adicionais acerca 
da conformação estrutural daqueles arranjos e da evolução do seu desempenho econômico e produtivo ao longo do tempo.

Tabela 12

Distribuição de empresas pelos clusters identificados nos diversos arranjos investigados

\begin{tabular}{l|l|c|c|c|c|c|c}
\hline \multicolumn{2}{c|}{} & Cluster 1 & Cluster 2 & Cluster 3 & Cluster 4 & Cluster 5 & Total \\
\hline \multirow{2}{*}{ Brasília } & $\mathrm{n}^{\mathrm{o}}$ & 7 & 13 & 14 & 7 & 11 & 52 \\
\cline { 2 - 8 } & $\%$ & 13,46 & 25,00 & 26,92 & 13,46 & 21,15 & 100 \\
\hline \multirow{2}{*}{ Curitiba } & $\mathrm{n}^{\mathrm{o}}$ & 6 & 4 & 3 & 3 & 9 & 25 \\
\cline { 2 - 8 } & $\%$ & 24,00 & 16,00 & 12,00 & 12,00 & 36,00 & 100 \\
\hline \multirow{2}{*}{ Petrópolis } & $\mathrm{n}^{\mathrm{o}}$ & 6 & 1 & 3 & 3 & 5 & 18 \\
\cline { 2 - 9 } & $\%$ & 33,33 & 5,56 & 16,67 & 16,67 & 27,78 & 100 \\
\hline \multirow{2}{*}{ Recife } & $\mathrm{n}^{\mathrm{o}}$ & 3 & 7 & 14 & 7 & 5 & 36 \\
\cline { 2 - 9 } & $\%$ & 8,33 & 19,44 & 38,89 & 19,44 & 13,89 & 100 \\
\hline \multirow{2}{*}{ Total } & $\mathrm{n}^{\mathrm{o}}$ & 22 & 25 & 34 & 20 & 30 & 131 \\
\cline { 2 - 9 } & $\%$ & 16,79 & 19,08 & 25,95 & 15,27 & 22,90 & 100 \\
\hline
\end{tabular}

Fonte: informações extraídas da Base de dados sobre APLs - RedeSist.

\section{Considerações finais}

Uma análise mais cuidadosa da indústria de software brasileira revela um importante conjunto de fortalezas, debilidades e oportunidades. Além da amplitude do mercado interno, que por si só constitui importante estímulo ao seu fortalecimento, o dinamismo da indústria está associado à flexibilidade e à criatividade de empresas e pessoal técnico, à sofisticação e à atratividade de alguns de seus segmentos e à capacidade de gerar soluções satisfatórias para um amplo leque de atividades econômicas. Dentre as principais debilidades da indústria, destacam-se a excessiva fragmentação da estrutura industrial e as dificuldades para implementar uma estratégia mais efetiva de internacionalização, capaz de se traduzir numa ampliação das exportações. Apesar desses problemas, é possível identificar uma série de oportunidades que podem ser exploradas para manter o dinamismo da indústria, as quais incluem não apenas segmentos nos quais as empresas brasileiras já consolidaram uma posição favorável - como no desenvolvimento de softwares para o setor financeiro, ERPs, e-business, aplicativos para telecomunicações, e-government e softwares formatados para atividades específicas, como agronegócios e varejo - como também novos segmentos que apresentam um potencial atrativo - como os relacionados a atividades mais complexas de outsourcing, ao desenvolvimento de softwares livres, jogos digitais, softwares de realidade virtual e soluções para atividades de broadcasting.

No contexto de uma economia crescentemente "baseada no conhecimento" a indústria de software assume uma importância particular. Partindo dessa constatação, a análise desenvolvida procurou ressaltar a 
complexidade, heterogeneidade e sofisticação da indústria brasileira de software, não apenas do ponto de vista da diversidade de produtos e serviços gerados, como também considerando a sua configuração empresarial e a sua distribuição espacial. Apesar dos problemas e desafios com os quais a indústria tem se defrontado nos últimos dez anos, a mesma mantém o seu dinamismo, possuindo potencial para amplificar o seu impacto econômico e para estimular a adoção de inovações por diferentes atividades econômicas, contribuindo para o aumento da produtividade e competitividade dessas atividades.

Através da análise realizada, procurou-se ressaltar que o processo de acúmulo de competências no setor de software possui uma dimensão espacial importante, refletindo também a estrutura essencialmente heterogênea dessa atividade. Quanto a esse aspecto, há indícios de que a proximidade territorial constitui um importante fator indutor da aceleração de mecanismos de aprendizado e de fortalecimento da competitividade empresarial naquele setor. Essa proximidade espacial é também importante na medida em que tende a induzir o surgimento de instituições e firmas com competências complementares, a partir das quais podem ser reforçadas práticas interativas - neste caso, essencialmente vinculadas a fluxos intangíveis de informações e conhecimentos - capazes de sustentar o dinamismo inovativo e a competitividade.

Partindo dessa hipótese, procurou-se utilizar procedimentos de estatística multivariada para identificar e analisar aglomerações produtivas espacialmente localizadas no setor de software. Com base nesses procedimentos, procurou-se avaliar o processo de construção de competências nesses arranjos, a partir de um estudo exploratório baseado em informações coletadas junto a empresas inseridas em quatro arranjos produtivos especializados em software. Apesar do caráter eminentemente exploratório do exercício empírico realizado, ele aponta no sentido da heterogeneidade do processo de construção de competências naquele setor. Essa heterogeneidade pode ser, em parte, explicada em função da amplitude e complexidade do mercado interno, que possibilita a sobrevivência e atuação de firmas produtoras de softwares extremamente díspares em termos de padrões de especialização, estratégias, competências e performances inovativas. Nesse contexto, há indícios de que os canais de intercâmbio de informações existentes naqueles arranjos devem ser ativados - por meio do manejo adequado dos instrumentos de política e da mobilização das instâncias locais de governança - de forma a possibilitar um salto qualitativo em termos da definição de padrões tecnológicos, de procedimentos de melhoria da qualidade e de práticas de certificação, impulsionando as empresas ao aprofundamento de seu esforço inovativo e à adoção de estratégias mercadológicas mais agressivas, orientadas, inclusive, para uma ampliação de exportações. 


\section{Bibliografia}

AREVOLO, W. Innovative program to develop and export Brazil's software. Gartner Group, CS-15-5090, Mar. 2002.

ARORA, A.; GAMBARDELLA, A. The globalization of the software industry: perspectives and opportunities for developed and developing countries. Cambridge, MA: National Bureau of Economic Research, 2004. (NBER Working Paper Series, Working Paper, 10538).

ASSESPRO, MBI e ITS. Exportações brasileiras de TI \& software. Pesquisa e relatório desenvolvido pela MBI, 2005. Disponível em: http://www.assespro-sp.org.br/.

ASSOCIAÇÃO BRASILEIRA DE EMPRESAS DE SOFTWARE. Bases de dados. 2007. Disponível em: http://www.abes.org.br/templ3.aspx?id=304\&sub=524.

ATKEARNEY e BRASSCOM. Desenvolvimento de uma agenda estratégica para o setor de IT Off-shore Outsourcing. Relatório final. Brasília, nov. 2005.

BOTELHO, A.; STEFANUTO, G.; VELOSO, F. The Brazilian software industry. Sept. 2003. Mimeografado.

BRITTO, J. Configuração espacial da indústria brasileira: Uma análise baseada na noção de aglomerações produtivas. In: ENCONTRO DA SOCIEDADE BRASILEIRA DE ECONOMIA POLÍTICA, 8, Florianópolis, jun. 2003.

Políticas de apoio a arranjos produtivos locais - uma sistematização de princípios e instrumentos. In: SEMINÁRIO ARRANJOS PRODUTIVOS LOCAIS, Universidade Estácio de Sá, 2005. Mimeografado.

; ALBUQUERQUE, E. M. Estrutura e dinamismo de clusters industriais na economia brasileira: uma análise exploratória a partir dos dados da RAIS. In: TIRONI, L. F. Industrialização descentralizada: sistemas industriais locais. Brasília: IPEA, 2001. cap. 1.

; CASSIOLATO, J. E.; STALLIVIERI, F.; GUIMARÃES, V. Sectoral system of innovation and local productive systems in the Brazilian software industry: a focus on competence building processes. In: CATCH UP MILANO MEETING, Milão, Itália, 5-8 set. 2006.

; STALLIVIERI, F.; CAMPOS, R. R.; VARGAS, M. Padrões de aprendizagem, cooperação e inovação em aglomerações produtivas no Brasil: uma analise multivariada exploratória. In: ENCONTRO NACIONAL DE ECONOMIA - ANPEC, Recife, 2007. Anais...

CAMPOS, R. R. Ampliando espaços de aprendizagem: um foco para políticas de estímulos aos arranjos produtivos locais. In: COLÓQUIO INTERNACIONAL DE DESENVOLVIMENTO LOCAL - UCDB, Campo Grande, MS, 2004.

; VARGAS, M. Forms of governance, learning mechanisms and localized innovation: a comparative analysis in local productive systems in Brazil. In: THE FIRST GLOBELICS CONFERENCE, Rio de Janeiro: UFRJ, 2003. CD Room. Anais... 
Jorge Britto / Fabio Stallivieri

CASSIOLATO, J. E.; GUIMARÃES, V.; LASTRES, H. M. M. Innovation systems for information and communication technologies: the case of Brazil. In: BASKARAN, A.; MUCHIE, M. (Ed.). Bridging the digital divide: innovation systems for ICT in Brazil, China, Thailand and Southern Africa. London: Adonis \& Abbey, 2006.

; LASTRES, H. M. M. O foco em arranjos produtivos e inovativos locais de micro e pequenas empresas. In: LASTRES, H. M. M.; CASSIOLATO, J. E.; MACIEL, M. L (Org.). Pequena empresa: cooperação e desenvolvimento local. Rio de Janeiro: Relume Dumará - UFRJ, Instituto de Economia, 2003. p. 21-34.

; SZAPIRO, M. Uma caracterização de arranjos produtivos locais de micro e pequenas empresas. In: LASTRES, H. M. M.; CASSIOLATO, J. E.; MACIEL, M. L. (Org.). Pequena empresa: cooperação e desenvolvimento local. Rio de Janeiro: Relume Dumará - UFRJ, 2003.

; VILLASHI, A. E.; CAMPOS, R. Local productive and innovative systems in Brazil: a policy perspective. In: CASSIOLATO J. E.; LASTRES H. M. M.; MACIEL M. L. (Ed.). Systems of innovation and development: evidence from Brazil. London: Edward Elgar, 2003.

COMMANDER, S. What explains the growth of a software industry in some emerging markets. Centre for New and Emerging Markets, London Business School, Apr. 2003. (DRC Working Papers, n. 22).

CompTIA. The critical role of the software industry in Latin America: a summary of studies conducted in eight Latin American markets. 2004. Mimeografado.

CROCCO, M. A.; GALINARI, R.; SANTOS, F.; LEMOS, M. B.; SIMÕES, R. Metodologia de identificação de aglomerações produtivas locais. Nova Economia, Belo Horizonte, v. 16, n. 2, p. 211-241, maio/ago. 2006.

Metodologia de identificação de arranjos produtivos locais potenciais: uma nota técnica. Belo Horizonte: CEDEPLAR-UFMG, abr. 2003. (Texto para Discussão, n. 191).

DUARTE, C. H. C. Brazil: cooperative development of a software industry. IEEE SOFTWARE May/Jun. 2002.

FERNANDES, A.; BALESTRO, M.; MOTTA, A. O arranjo produtivo local de software do Distrito Federal. Relatório de Atividades da Expansão da RedeSist. Instituto de Economia - Universidade Federal do Rio de Janeiro (IE/UFRJ), set. 2004.

GAIO, F. Software strategies for developing countries. In: SCHMITZ, H.; CASSIOLATO, J. (Ed.). Hi-tech for industrial development - Lessons from the Brazilian experience in eletronics and automation. London: Routledge, 1992.

IDC-ABES. Associação Brasileira de Empresas de Software. Mercado brasileiro de software panorama e tendências 2007. 2007. Disponível em: www.abes.org.br.

JOHNSON, R. A.; WICHERN, D. W. Applied multivariate statistical analysis. 4. ed. Upper Saddle River: Prentice-Hall, 1998.

LASTRES, H.; CASSIOLATO, J. E. Innovation systems and local productive arrangements: New strategies to promote the generation, acquisition and diffusion of knowledge. Innovation: Management, Policy \& Practice, v. 7, n. 2-3, Apr./Aug. 2005. 
LASTRES, H. M. M. et al. Interagir para competir: promoção de arranjos produtivos e inovativos no Brasil. Brasília: SEBRAE /FINEP/CNPq, 2002.

; LEMOS, C.; VARGAS, M. Novas políticas na economia do conhecimento e do aprendizado. Nota Técnica 25, Bloco 3. In: CASSIOLATO, J.; LASTRES, H. (Org.). Arranjos e sistemas produtivos locais e as novas políticas de desenvolvimento industrial e tecnológico. Rio de Janeiro: IE/UFRJ, 2000.

LÓPEZ, A. (Coord.). Complementación productiva en la industria del software en los países del Mercosur: impulsando la integración regional para participar en el mercado global. Swiss Agency for Development and Cooperation - SCD (Suiza), 2007. Mimeografado.

MBI. Panorama da indústria latino-americana de software. MBI Mayer \& Bunge Informática Ltda., 2005.

OECD. OECD Information technology Outlook. Organization for Economic Cooperation and Development, 2006.

ROSELINO, J. E. Análise da indústria brasileira de software com base em uma taxonomia das empresas: subsídios para apolítica industrial. Revista Brasileira de Inovação, v. 5, n. 1, p. 157-201, jan./jun. 2006a.

A indústria de software: o 'modelo brasileiro' em perspectiva comparada. Tese (Doutorado)-Instituto de Economia. Unicamp, Campinas, 2006b.

SANTOS, F.; CROCCO, M.; LEMOS, M. B. Arranjos e sistemas produtivos locais em 'espaços industriais' periféricos: estudo comparativo de dois casos brasileiros. Revista de Economia Contemporânea, Rio de Janeiro, v. 6, n. 2, p. 147-180, jul./dez. 2002.

SCATOLIN, F. D.; SAMPAIO, S. E. K. O arranjo produtivo de software em Curitiba / PR. 2004. Disponível em: http://www.neitec.ufsc.br/cd_relatorio/arranjos_produtivos _ locais/Artigo_Sergio_e_Scatolin-Software_de_Curitiba.pdf.

SCHMITZ, H.; NADVI, K. Clustering and industrialization: introduction. World Development, v. 27, n. 9, Sept. 1999.

SOFTEX. Perfil das empresas brasileiras exportadoras de software. Campinas: SOFTEX, 2005.

SOFTEX-MIT. Indústria de software no Brasil - 2002: fortalecendo a economia do conhecimento. Massachusetts Institute of Technology (MIT) / Brasil, coordenação geral Sociedade SOFTEX. Campinas, 2002. 80p.

STALLIVIERI, F.; CAMPOS, R. R.; BRITTO, J. Capacitações tecnológicas de micro e pequenas empresas inseridas em redes tecno-produtivas: o caso da eletrometal-mecânica em Joinville/SC. Revista de Economia Contemporânea, Rio de Janeiro, v. 11, n. 2, p. 439474, 2007.

STEFANUTO, G. N. O Programa Softex e a indústria de software no Brasil. Tese (Doutoramento)-Instituto de Geociências, DPCT, Unicamp, Campinas, 2004.

; CARVALHO, R. Q. Perfil das empresas brasileiras exportadoras de software. Campinas: DPCT/IG Unicamp, e Observatório Digital Softex, 2005. 
Jorge Britto / Fabio Stallivieri

SUZIGAN, W. Aglomerações industriais como foco de políticas. Aula Magna do XXVIII Encontro Nacional de Economia, Campinas, dez. 2000.

(Coord.). Arranjos produtivos locais e o novo padrão de especialização regional da indústria paranaense na década de noventa. Curitiba: Ipardes, 2003.

Clusters ou sistemas locais de produção: mapeamento, tipologia e sugestões de políticas. Revista de Economia Política, v. 24, n. 4, out./dez. 2004.

(Coord.). Identificação, mapeamento e caracterização estrutural de arranjos produtivos locais no Brasil. Relatório Consolidado, IPEA-DISET, out. 2006.

Designing policies for local production systems: a methodology based on evidence from Brazil. Revista Economia, Brasília, DF, v. 8, n. 1, p. 161-186, jan./apr. 2007.

; FURTADO, J.; GARCIA, R. Estruturas de governança em arranjos ou sistemas locais de produção. Gestão da Produção, São Carlos, v. 14, n. 2, p. 425-439, maio/ago. 2007.

; FURTADO, J.; GARCIA, R; SAMPAIO, S. Coeficientes de Gini locacionais (GL): aplicação à indústria de calçados do Estado de São Paulo. Nova Economia, v. 13, n. 2, p. 39-60, jul./dez. 2003.

TIGRE, P. B.; MARQUES, F. S. Capítulo III: Brasil. In: LÓPEZ, A. (Coord.). Complementación productiva en la industria del software en los países del Mercosur: impulsando la integración regional para participar en el mercado global. Swiss Agency for Development and Cooperation - SCD (Suiza), 2007. Mimeografado.

VELOSO, F.; BOTELHO, A.; TSCHANG, T.; AMSDEM, A. Slicing the knowledgebased economy in Brazil, China and India: a tale of 3 software industries. Campinas, SP, Brazil: Softex, 2003. 